\title{
Review
}

\section{The European Radiation Dosimetry Group - Review of Recent Scientific Achievements}

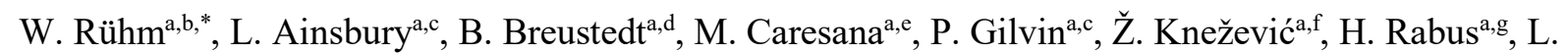
Stolarczyk $^{\mathrm{a}, \mathrm{h}, \mathrm{i}}$, A. Vargas ${ }^{\mathrm{a}, \mathrm{j}}$, J.F. Bottollier-Depois ${ }^{\mathrm{a}, \mathrm{k}}$, R. Harrison ${ }^{\mathrm{a}, \mathrm{l}}$, M.A. Lopez ${ }^{\mathrm{a}, \mathrm{m}}$, H. Stadtmann ${ }^{\mathrm{a}, \mathrm{n}}$, R. Tanner,a, , F. Vanhavere ${ }^{\mathrm{a}, \mathrm{o}}$, C. Woda ${ }^{\mathrm{a}, \mathrm{b}}$, I. Clairand ${ }^{\mathrm{a}, \mathrm{k}}$, E. Fantuzzi ${ }^{\mathrm{a}, \mathrm{p}}$, P. Fattibene ${ }^{\mathrm{a}, \mathrm{q}}$, O. Hupe $\mathrm{H}^{\mathrm{a}, \mathrm{g}}$, P. Olko $^{\mathrm{a}, \mathrm{i}}$, V. Olšovcováa ${ }^{\mathrm{a}, \mathrm{r}}$, H. Schuhmacher ${ }^{\mathrm{a}, \mathrm{g}}, \mathrm{J}$.G. Alves ${ }^{\mathrm{a}, \mathrm{s}, \mathrm{t}}, \mathrm{S}$. Miljanic ${ }^{\mathrm{a}, \mathrm{f}}$,

a) EURADOS, EURADOS e.V. Postfach 1129, D-85758 Neuherberg, Germany

b) Helmholtz Center Munich, Institute of Radiation Medicine, D-85758 Neuherberg, Germany

c) Public Health England, Chilton, Didcot, OXON OX11 0RQ, UK

d) Karlsruhe Institute of Technology, Karlsruhe, Germany

e) Politecnico di Milano, Milan, Italy

f) Ruđer Bošković Institute (RBI), Zagreb, Croatia

g) Physikalisch-Technische Bundesanstalt (PTB), Braunschweig, Germany

h) Skandion, Uppsala, Sweden

i) Instytut Fizyki Jądrowj (IFJ), Krakow, Poland

j) Universitat Politecnica de Catalunya, Instituto de Tècniques Energètiques, Barcelona, Spain

k) University of Newcastle, Newcastle, UK

1) Institut de Radioprotection et de Sûreté Nucléaire (IRSN), Fontenay-aux-Roses, France

m) Centro de Investigaciones Energéticas Medioambientales y Tecnológicas (CIEMAT), Madrid, Spain

n) Seibersdorf Laboratories, Seibersdorf, Austria

o) Belgian Nuclear Research Centre (SCK-CEN), Mol, Belgium

p) ENEA Italian National Agency for New Technologies, Energy and Sustainable Economic Development, Radiation Protection Institute, Bologna, Italy

q) Istituto Superiore di Sanitá (ISS), Rome, Italy

r) ELI Beamlines, Dolní Břežany, Czech Republic

s) Universidade de Lisboa (UL), Instituto Superior Técnico (IST), Laboratório de Proteção e Segurança Radiológica (LPSR), Estrada Nacional 10, 2695-066 Bobadela LRS, Portugal

t) Departamento de Engenharia e Ciências Nucleares (DECN), Centro de Ciências e Tecnologias Nucleares $\left(\mathrm{C}^{2} \mathrm{TN}\right)$, do IST

* Corresponding author:

Werner Rühm

German Research Center on Environmental Health (GmbH)

Institute for Radiation Medicine

Ingolstädter Lanstr. 1

85764 Neuherberg

E-mail: werner.ruehm@,helmholtz-muenchen.de (W. Rühm)

Key words: EURADOS, radiation dosimetry, ionizing radiation 


\section{ABSTRACT}

The European Radiation Dosimetry Group (EURADOS) is a network of organizations and scientists promoting research and development in the dosimetry of ionizing radiation, contributing to harmonization in dosimetry practice across Europe, and offering education and training in areas relevant for dosimetry. As a registered non-profit association under German law, EURADOS is currently running eight active working groups (WGs): WG2 on "Harmonization of Individual Monitoring", WG3 on "Environmental Dosimetry", WG6 on "Computational Dosimetry", WG7 on "Internal Dosimetry", WG9 on "Dosimetry in Radiotherapy", WG10 on "Retrospective Dosimetry", WG11 on "Dosimetry in High-Energy Radiation Fields", and WG12 on "Dosimetry in Medical Imaging". This paper presents recent scientific results obtained within these working groups, and additionally highlights the role of EURADOS as an organization which contributes to the development of a systematic strategy of radiation protection research in Europe.

\section{Introduction}

Since the discovery of X-rays by Wilhelm Conrad Roentgen in 1895, protection of humans against the detrimental effects of ionizing radiation has been an issue. Based on the first experience of those working with the newly developed X-ray tubes, the avoidance of tissue effects such as skin burns induced by comparatively high doses was the most important issue. In contrast, in later years, and in particular after the atomic bombings of Hiroshima and Nagasaki in Japan, protection of humans against stochastic health effects such as cancer or leukemia has become of increasing concern. Quantification of the radiation doses involved in any exposure scenario turned out to be indispensable to avoid any of the observed radiationinduced health effects. Consequently, the past 120 years saw continuous efforts to develop instruments for the detection and quantification of radiation, for various radiation types at energy ranges spanning many orders of magnitude, and for any incidence angles. In parallel, the International Commission on Radiation Units and Measurements (ICRU) developed concepts of various operational quantities such as ambient dose equivalent, personal dose equivalent, etc., in an effort to quantify the radiation protection quantities such as equivalent dose and effective dose proposed by the International Commission on Radiological Protection (ICRP). 
Since its foundation in 1982, the European Radiation Dosimetry Group (EURADOS) has been fostering research and development in the dosimetry of ionizing radiation and has been contributing towards the harmonization of the dosimetry in Europe. EURADOS actively supports the harmonization in dosimetry by organizing intercomparison exercises including various instruments such as whole body dosimeters, finger ring dosimeters, dosimeters for the lens of the eye, partial body and whole body counters, but also computational methods such as neutron unfolding techniques, Monte Carlo simulations, dose calculation procedures, etc. Research and development is another area where EURADOS has much to contribute. Emerging new radiation sources such as pulsed high-energy fields at laser laboratories or accelerators often requires development of new instrumentation. Measurement campaigns organized by EURADOS in Europe and beyond allow participants to compare response of any newly developed instruments and identify advantages and disadvantages of various approaches employed.

As of 2019, EURADOS involves 73 institutional members including, i.e., research centers, universities, and dosimetry services, from more than 30 countries. Currently, EURADOS is running eight active Working Groups (WGs) which all contribute to the overall EURADOS mission. These Working Groups are WG2 on "Harmonization of Individual Monitoring", WG3 on "Environmental Dosimetry", WG6 on "Computational Dosimetry", WG7 on "Internal Dosimetry", WG9 on "Dosimetry in Radiotherapy", WG10 on "Retrospective Dosimetry", WG11 on "Dosimetry in High-Energy Radiation Fields", and WG12 on "Dosimetry in Medical Imaging". More details on the structure and governance of the network are given in (Rühm and Schumacher 2017). The working program of the EURADOS WGs has recently been summarized (Rühm et al. 2018), and an overview on education and training actions including intercomparison exercises has been presented (Alves et al. 2019). The present paper summarizes recent scientific achievements obtained by EURADOS and its Working Groups.

\section{Strategic Research Agenda in dosimetry for Europe}

Recent years have seen an increasing effort in Europe to develop radiation protection research based on a multi-disciplinary approach. The key process in this approach is bringing together various research platforms that contribute to radiation protection research, namely 
EURADOS, MELODI, ALLIANCE, NERIS and EURAMED, and more recently SHARE. MELODI is the Multidisciplinary European Low Dose Initiative focussing on health effects of low-dose and low dose rate ionizing radiation (www.melodi-online.eu). ALLIANCE (www.er-alliance.org) aims at maintaining and enhancing radioecological competences and experimental infrastructures in Europe and "addresses scientific and educational challenges in assessing the impact of radioactive substances on humans and the environment". NERIS (European Platform on Preparedness for Nuclear and Radiological Emergency Response and Recovery) has the mission "to establish a forum for dialogue and methodological development between all European organisations and associations taking part in decision making of protective actions in nuclear and radiological emergencies and recovery in Europe.“ (www.eu-neris.net). EURAMED (European Alliance for Medical Radiation Protection Research) is an umbrella structure of several European organizations representing the medical field. (www.euramed.eu). Finally, SHARE is the research platform that deals with integration of social sciences and humanities into radiation protection research (www.ssh-share.eu). Each of these research platforms has been developing their own strategic research agendas (SRAs) and roadmaps, to guide the research in their specific field in Europe, for the next 20 years. The challenge is now to combine these individual SRAs and roadmaps, to finally develop a joint SRA and roadmap for radiation protection research for Europe. Details of this process were recently summarized (Rühm et al. 2017a).

In 2013 the EURADOS Council established a task group to develop an SRA for dosimetry in Europe. The task group collected input from all active WGs and formulated five major visions on how dosimetry could be improved during the next 20 years, namely: 1) To update fundamental dose concepts and quantities, 2) To improve radiation dose estimates for epidemiological cohorts, 3) To develop efficient dose assessment concepts for radiological emergencies, 4) To integrate personalized dosimetry in medical applications, and 5) To improve radiation protection of workers and the public. Each of these visions included a number of identified challenges which are detailed by means of specific research lines. Computational dosimetry as a cross-cutting approach, as well as education and training, and harmonization in dosimetry, were treated as separate issues. The EURADOS SRA was published as a EURADOS report (Rühm et al. 2014) and a shortened version was published in the peer-reviewed scientific literature (Rühm et al. 2016). 
Since the publication of the EURADOS SRA, any proposal submitted to the European Commission (EC) in response to an EC call in radiation protection research should demonstrate how the EURADOS SRA and/or the SRAs of the other European research platforms mentioned above are considered in the proposal.

Because research in radiation protection is progressing and because views from other international organizations interested in the dosimetry of radiation protection would be helpful, EURADOS has since then initiated efforts to update its SRA. As a first step, a stakeholder workshop was organized in 2017 in Neuherberg, Germany, and comments from 22 international organizations present at the workshop were collected. The results were published as EURADOS Report 2017-01 (Rühm et al. 2017b). Currently, the EURADOS SRA is being updated with input from this stakeholder workshop, and input from all EURADOS Working Groups, considering also recently funded research projects.

\section{WG 2 "Harmonisation of Individual Monitoring"}

During the 1990s EURADOS identified that varying approaches to radiation protection in different organisations and countries were giving rise to varying standards of protection (dosimetry performance). Following a publication of the European Council Directive 96/29/Euratom (the Basic Safety Standards Directive), an action on Harmonisation was set up with the aim of promoting quality and equality of performance, so that workers in different countries could expect the same standards of protection. The aim was not to require all organisations do things in exactly the same way, but to optimise their different ways in order to achieve the same standards. To meet this goal, in 2006 the European Commission (EC) issued a call for a tender on the establishment of the European technical recommendations for monitoring individuals exposed to external radiation, which was awarded to a consortium comprising the Greek Atomic Energy Commission and EURADOS. The project led to the publication of Radiation Protection 160 document in 2009 (European Commission 2009). Many of the activities of EURADOS, across all the working groups, promote harmonisation (see Introduction, above); for example, many of the Working Groups conduct intercomparisons in their respective areas. Working Group 2 (WG2), however, was specifically set up to deliver the harmonisation action, and its activities are all directed to that end. These activities include those directed at discovering and monitoring the level of 
harmonisation (organizing surveys to assess how legislation and/or the EU Technical Recommendations are implemented in each country (Gilvin et al, 2014), as well as networking among individual monitoring services (IMS) and those directed at improving it (technical recommendations, training courses on its implementation, learning networks, online forum and intercomparisons).

The training courses on the European technical recommendations on individual monitoring for external radiation continue to be successful, as illustrated by participant feedback, and to be well-attended. In total over 180 scientists and administrators, mainly from IMS but also from regulatory bodies and metrology laboratories, have attended the five courses delivered since 2012 (Alves et al. 2019). The content of the course has evolved in the light of scientific developments (for example, there is now a session on eye lens dosimetry) and of feedback (participants suggested extra emphasis on the topics of uncertainty evaluation and quality management). Other current efforts include regular learning networks and a project to produce guidance to assist IMS and auditors in quality management.

The most important and successful aspect of WG2 efforts on harmonisation has been the delivery of a continuing programme of self-sustaining intercomparison exercises to assess the performance of measurement devices (whole body dosemetes for photon and beta radiation fields, extremity dosemeters for photon and beta fields, neutron dosemeters for mixed photon and neutron radiation fields, and more recently extremity and eye-lens dosemeters). These have proved very popular amongst IMS, with up to 120 systems participating and with concrete and useful outcomes. The intercomparisons are funded on a cost recovery basis from participant fees, and the programme has been running since 2008 (Grimbergen et al. 2016, Romero et al. 2016). Intercomparisons for whole-body photon/beta dosemeters (Figel et al. 2016, Stadtmann et al. 2016) are held in alternate years, with intercomparisons for extremity photon/beta (Stadtmann et al. 2017) and for whole body neutron dosemeters (Chevallier et al, 2016) in the other years. A recent development has been to include eye lens dosemeters, following work by WG12, alongside the extremity types. Intercomparisons are completed at well-attended, lively participants' meetings, with the results summarised in EURADOS reports as well as being presented at conferences and published in the open literature. Example outputs are given below (Figs. $1-5)$. 


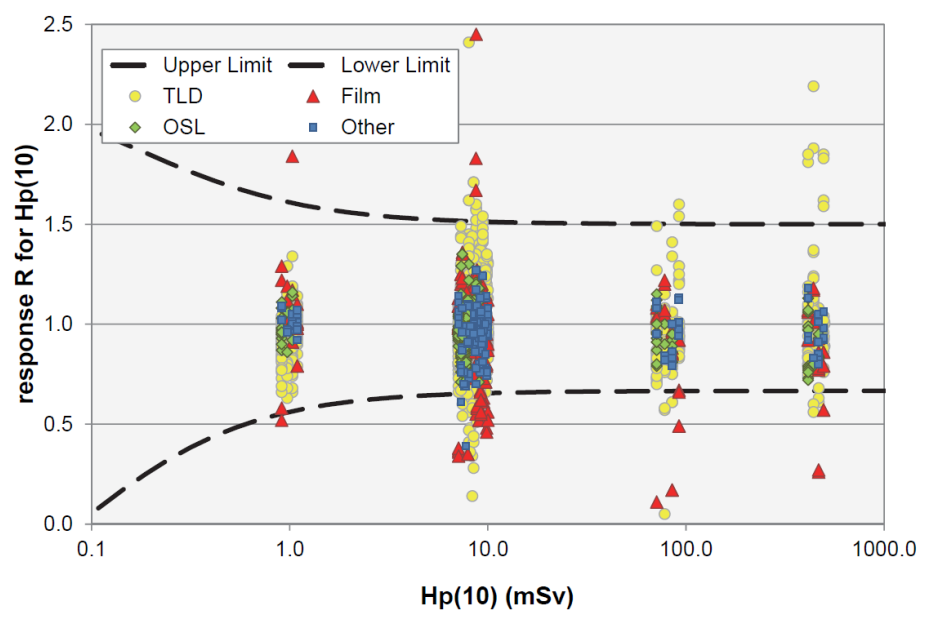

Fig. 1. Performance of 112 systems in a whole body photon/beta intercomparison. $5 \%$ of the results lie outside the limits (Stadtmann et al. 2018).

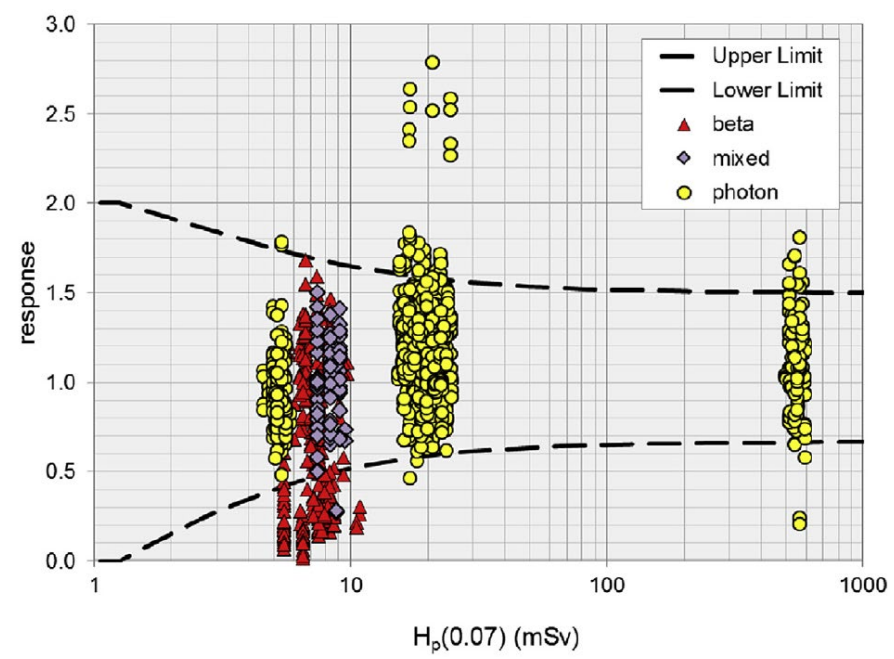

Fig. 2. Extremity intercomparison, 72 systems. 13\% outliers - some systems have difficulty with beta irradiations. In this case the problems chiefly arise at lower beta energies $\left({ }^{85} \mathrm{Kr}\right)$ and higher angles of incidence $\left({ }^{90} \mathrm{Sr} /{ }^{90} \mathrm{Y}, 60^{\circ}\right)$ (Stadtmann et al. 2017). 


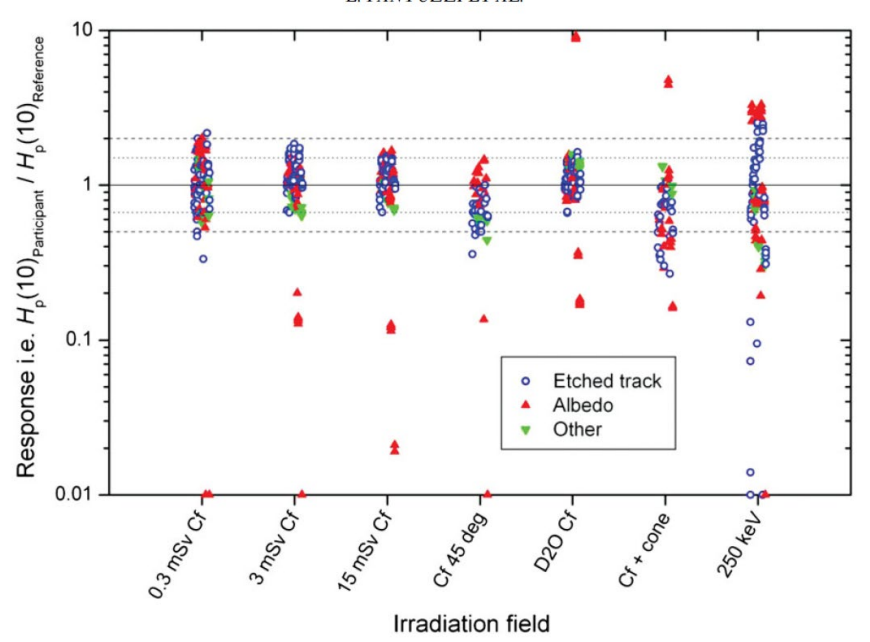

Fig. 3. Neutron intercomparison, 32 participants. Notice the number of outliers at $250 \mathrm{keV}$, the lower end of the fast neutron range, irrespective of technique (Fantuzzi et al. 2014).

In each of these examples, some systems perform better than others. The information and dialogue from intercomparisons can be used by dosimetry scientists in all services to improve their performance. All results are anonymised, but individual participants are able to see how their own systems perform in relation to others. Figures 4 and 5 show summary data for one high-performing and one low-performing system. The latter clearly has a problem with calibration.

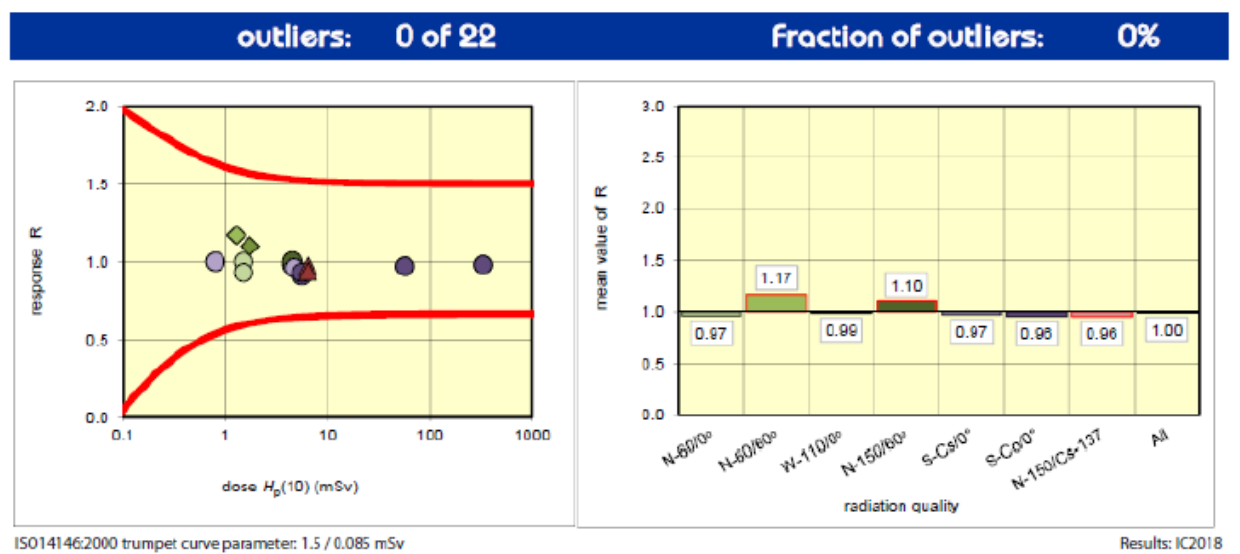

Fig. 4. Example data for a high-performing system (Figel et al., in prep). 


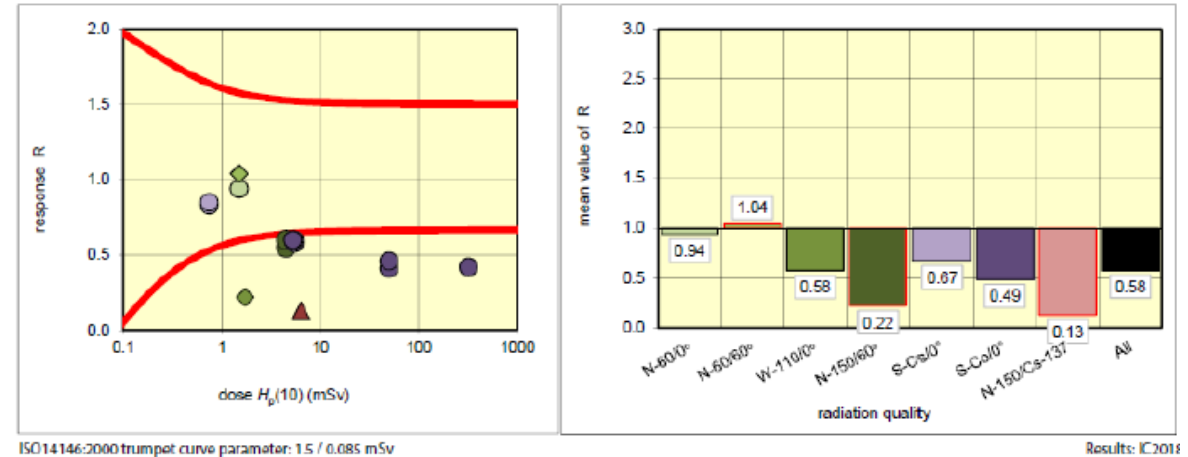

Fig. 5. Example data from a low-performing system (Figel et al., in prep).

Some regular participants have reported improved results between successive intercomparisons, often achieved by reviewing their traceability or calibration methods but in some cases by adapting their dosemeter design. This clearly shows the value of the intercomparison programme, and many participants are able to refer to it in their quality management systems as evidence of proficiency testing.

WG2 will continue to offer these programmes for as long as demand continues.

\section{WG3 "Environmental Dosimetry"}

The protection of the public against ionising radiation and radioactive contaminations caused by nuclear or other radiologically accidents may affect thousands of people. Following a radiological event, radiation protection authorities and other decision makers need quick and credible information on affected and contaminated areas. In Europe, at present, more than 5,000 stations make radiological monitoring data available in nearly real-time. In case of a nuclear emergency, national dose rate data have to be provided to the European Commission (EC) on an hourly basis, via the EUropean Radiological Data Exchange Platform (EURDEP). Based on these and other radiologically relevant data, the EC, which is in charge of the European Community Urgent Radiological Information Exchange System (ECURIE), may issue recommendations to the EU member states which could affect millions of people and may have severe economic and sociological consequences. In this context and in the framework of EURDOS several comparisons of dose rate monitors have been carried out in the past years, in order to study and harmonize the variety of detectors currently installed in the early warning stations. 


\subsection{Active dosimetry and spectrometry for radiological monitoring}

Recently, the development of new active detector systems based e.g. on $\mathrm{LaBr}_{3}, \mathrm{CdZnTe}$ and $\mathrm{CeBr}_{3}$ detectors, which allow to provide ambient dose rate values as well as spectrometric nuclide-specific data on contamination levels in real time, are being installed in radiological networks. The application of different methodologies to convert the spectra from such detectors to $H^{*}(10)$ has been investigated in WG3. For example, the so-called stripping methodology has been developed and applied to a $\mathrm{LaBr}_{3}$ detector for laboratory and longterm measurements in an early warning station (Camp and Vargas, 2013). In both cases the $H^{*}(10)$ values provided by the $\mathrm{LaBr}_{3}$ detector were in agreement with the reference values of the laboratory and with those provided by dose rate monitors in the surveillance station. Because there was a need for the harmonization and standardization of spectrometric units on a European scale, the European Project MetroERM (Metrology for radiological early warning networks in Europe, $1^{\text {st }}$ June 2014 to $31^{\text {st }}$ May 2017) was initiated were members of WG3 were among the core partners. During this collaboration, new spectrometry systems based on scintillators like $\mathrm{LaBr}_{3}, \mathrm{CeBr}_{3}, \mathrm{SrI}_{2}$, and the semiconductor $\mathrm{CdZnTe}$, were characterised experimentally and by use of various Monte Carlo (MC) simulations, so that they can also be used as dosemeters. More specifically, a comparison of spectrometers to be used as dose rate monitors under well-defined irradiation conditions was carried out at the reference measuring sites of the German Physikalisch Technische Bundesanstalt (PTB) for low dose rates. For example, detectors were irradiated under reference conditions at the PTB low-dose irradiation facility in the underground laboratory UDO II, at a floating platform on a lake (measuring site for cosmic radiation) and at a free-field irradiation facility (plume simulation machine). The results of the comparison show that the spectrometer monitors are superior to conventional dosemeters as can be seen in Fig. 6.
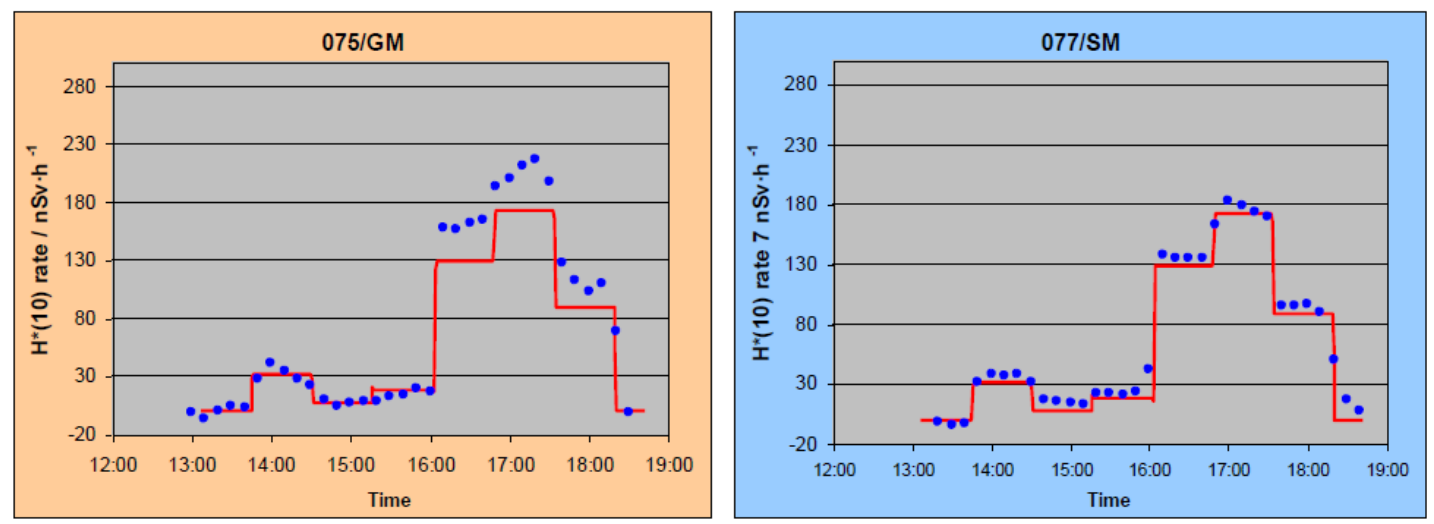
Fig. 6. Measured plume profiles of a Geiger-Müller monitor (left) and a $\mathrm{LaBr}_{3}$ detector (right) in comparison with the reference (red line).

Furthermore, among other activities, a 1-year comparison of different methods based on stripping, conversion coefficients and Maximum Likelihood Estimation using Expectation Maximization (ML-EM) in calculating the $H^{*}(10)$ rates from photon pulse-height spectra acquired with a spectrometric $\operatorname{LaBr}_{3}(\mathrm{Ce})(1.5 " \mathrm{x} 1.5$ ") detector have been evaluated at the reference station ESMERALDA in Madrid, Spain (Vargas et al. 2018). The results provided results similar to those obtained with a reference ionization chamber. In Fig. 7 the $H^{*}(10)$ rates calculated using the different methods, the measured data and the radon progeny concentrations during the period are shown. The bias between the $H^{*}(10)$ values obtained when using the different methods are included in the uncertainties. The bias of the ionization chamber was explained mainly because the device was not corrected for temperature changes. Figure 2 also demonstrates the influence of radon progeny on $H^{*}(10)$, due to their presence in air (days 1,2,3,5,6 and 8) and deposited on the ground during a rainy period (day 7).

It is concluded that spectrometric detectors should be installed at early warning stations, in order to complement existing "classical" dosemeters. This is currently going on in the Spanish early warning stations. In addition, the long-term performance of various dose rate monitors and spectro-dosemeters was tested under real weather conditions at the German Federal Office of Radiation Protection at the INTERCAL station (near Freiburg, Germany). 


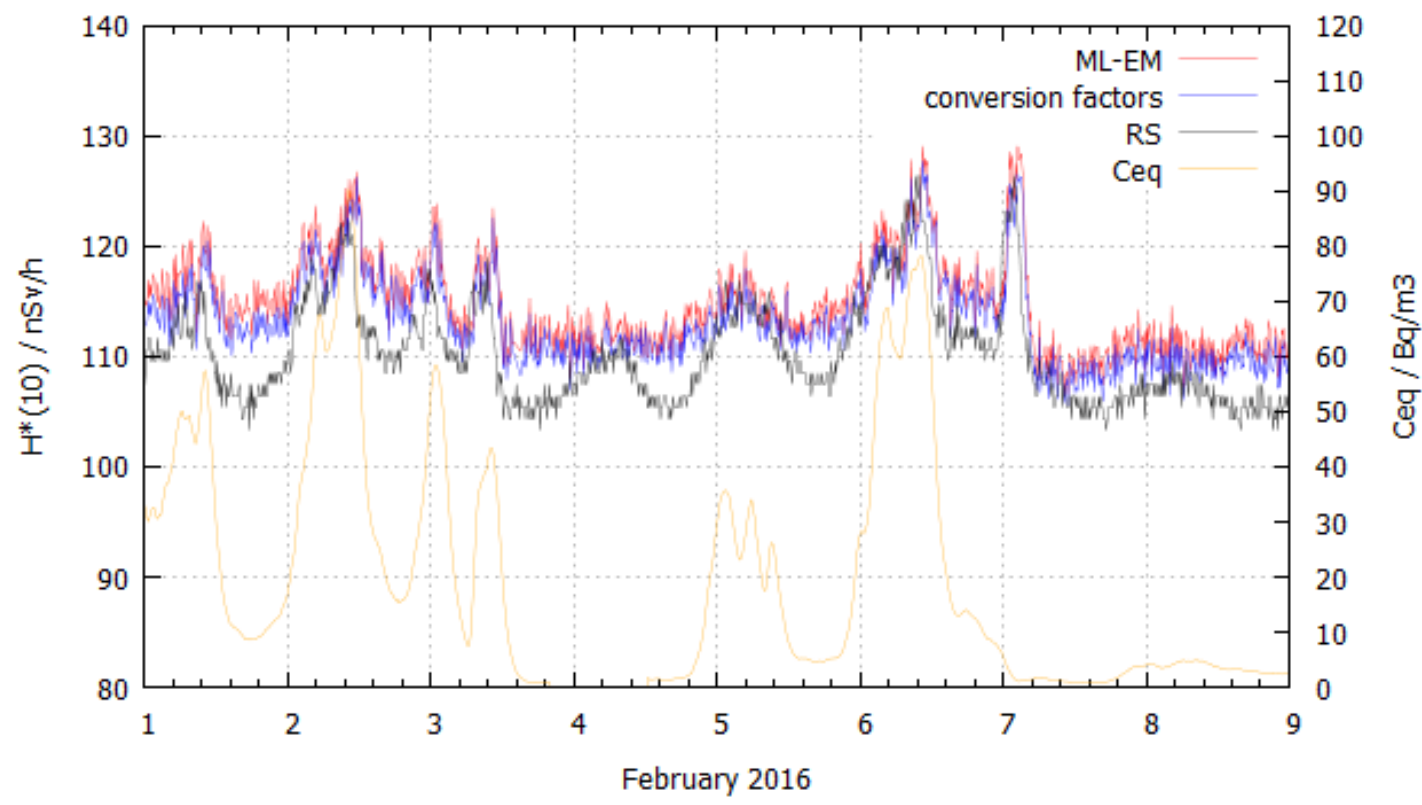

Fig. 7. Ambient dose equivalent rate calculated with different methods ML-EM, conversion factors) and measured with an ionization chamber (RS), and radon progeny concentrations for comparison (yellow line).

Following the MetroERM project, the Preparednes project (Metrology for mobile detection of ionising radiation following a nuclear or radiological incident) started in August 2017. Three of the four objectives of this project are closely linked to WG3, i.e., i) to develop unmanned aerial detection systems installed on aerial vehicles and helicopters for the remote measurement of dose rates and radioactivity concentrations., ii) to investigate the metrological relevance of 'crowd sourced monitoring' (non-governmental networks) data on dose rates and provide recommendations on the usability of such data and iii ) to establish stable and reproducible procedures to measure ambient dose equivalent rates using passive dosimetry.

Regarding the use of Unmanned Aerial Vehicles (UAVs) for dose rate and activity concentration measurements using spectrometric detectors, different detectors have been mounted on suitable drones (Fig. 8) and tests have been carried out to verify their operability. In Fig. 9 the results of a test flight using a Tc-99m source is shown. The software used was an extension of the RIMA code developed by the Technical University of Catalonia (UPC) (Royo et al. 2019). 


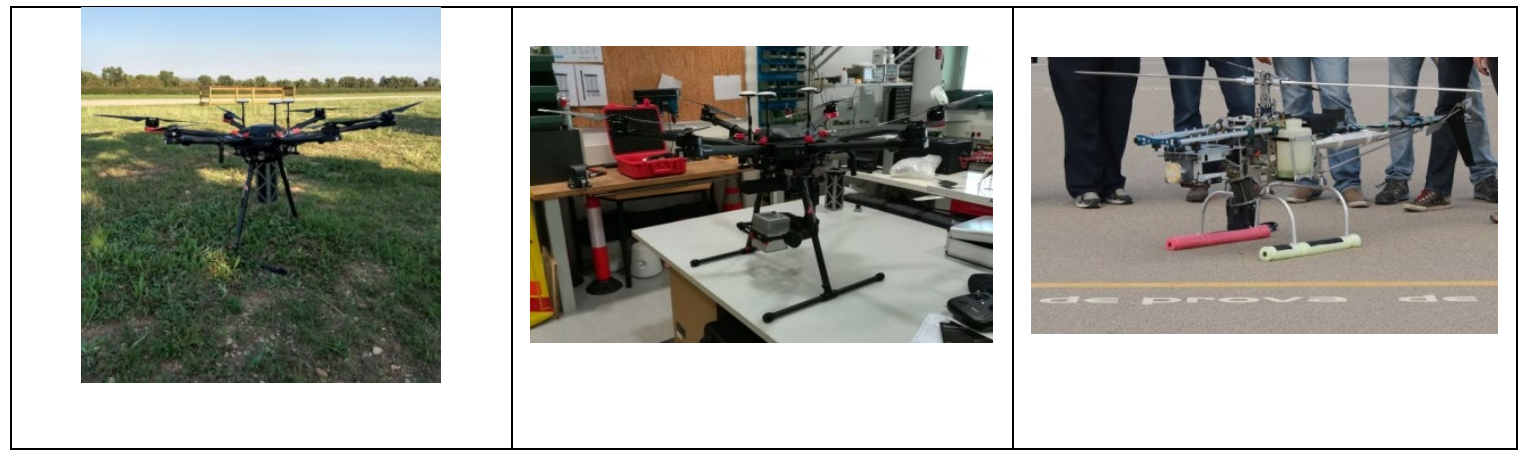

Fig. 8. Unmanned Aerial Vehicles (UAVs) with spectrometric detectors tested by WG3. Left: DJI Matrice 600 Pro with a NaI detector of 2"x"2 from Brideport Company. Center: DJI Matrice 600 Pro with a localizator detector from AISENSE company mounted in Gimbal. Right: Petrol engine helicopter Copterworks with a NaI of 3"x3".

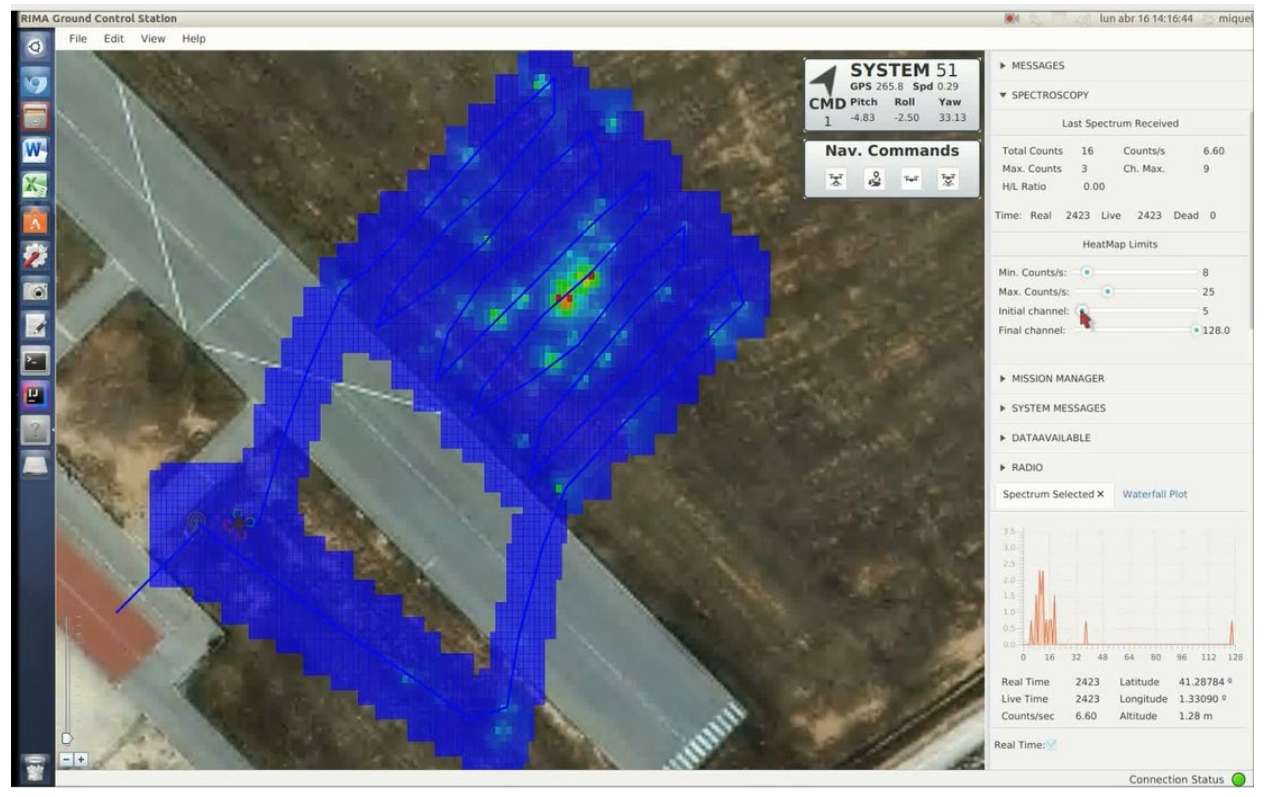

Fig. 9. On line screen screenshot of RIMASpec ground control station (Royo et al. 2019). Tc$99 \mathrm{~m}$ source is clearly detected,

Additionally, WG3 examined systems and methods used by non-governmental networks to measure external ionising radiation and to map areal contamination on the basis of a web study and a questionnaire completed by network managers. A number of measuring devices from different suppliers, which are used by the networks to measure radioactivity, were selected and will be tested and compared. In parallel, the production of a newly developed dose rate detector has started, based on a simplification of an existing instrument. 


\subsection{Passive dosimetry for radiological monitoring}

In the past, four comparisons of passive $H^{*}(10)$ area photon dosemeters were organized in collaboration with WG3: i) two years, from autumn 2005 until autumn 2007 in cooperation with the AKD workshop of the German Swiss Radiation Protection Association, ii) six months, from autumn 2011 until spring 2012, iii) three or six months, from spring 2014 and iv) six months, from autumn 2017 in the framework of the Preparedness.

Results of the EURADOS intercomparisson of passive $H^{*}(10)$ area dosemeters in 2014 are described in Dombrowski et al. 2017: Each of the 30 participants sent 16 passive dosemeters of one type to PTB -12 dosemeters were used for three different irradiations and four dosemeters were used to monitor any doses during transport; these four dosemeters were stored under lead shielding in the PTB underground laboratory UDO II. The three irradiations included i) four dosemeters exposed to only cosmic radiation on a floating platform on a lake, ii) eight dosemeters exposed to terrestrial and cosmic radiation at the reference site of PTB, and iii) four of these eight dosemeteres were irradiated additionally in a primary ${ }^{137} \mathrm{Cs}$ field of PTB facility. The results showed that the differences in the measured doses were less than 20 $\%$ and that an excess dose rate of $0.1 \mathrm{mSv}$ per year could not be measured. It was also shown that the dosemeters overestimated the cosmic radiation and underestimated the terrestrial radiation and, also, that some detectors were not watertight leading to a potential change in their radiation response.

Another comparison was performed to investigate the technical properties and typical precision of 38 passive area dosimetry systems from 34 European participants. In addition to previous comparisons, the response of the detectors as function of the photon angular distribution was studied. In some cases, a strong dependence of the response on the angle of incidence was observed.

In order to gain an overview of passive environmental dosimetry practices in Europe, WG3 carried out a survey which focused, among other issues, on the harmonization in terminology, uncertainty assessment procedures and corrections of measured values by passive dosemeters due to transport and climate (Duch et al. 2017). The questionnaire of the survey was answered by 47 institutions from 24 different countries, which issue approximately 10.000 area dosemeters per year. 
In 2017 (IC2017calm) and 2018 (IC2018calm) WG3 organized two comparison campaigns of calibration methods for passive area dosemeters. Each laboratory irradiated five dosemeters from the Karlsruhe Institute of Technology, Germany (KIT), and had another five for background measurements. The irradiated and the background dosemeters were sent to and analyzed by KIT. The measured $H^{*}(10)$ were compared to the values reported by the participants (Fig. 10).

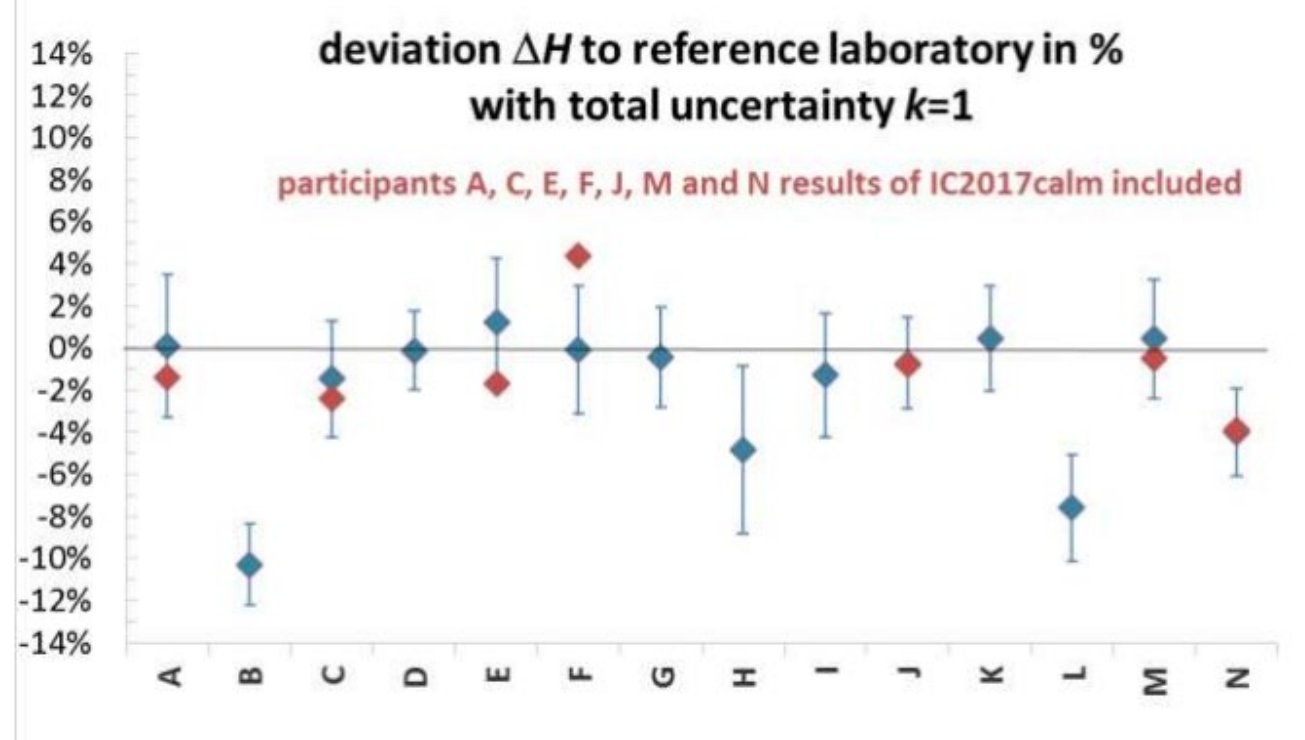

Fig 10. Results of the WG3 intercomparison campaigns IC2018calm and IC2017calm of calibration methods for passive area dosemeters.

\section{WG6 "Computational Dosimetry"}

\subsection{Dose quantities and conversion coefficients (together with WG10)}

For relatively low doses of ionizing radiation, i.e. those in which stochastic effects are the primary concern because the thresholds for tissue reactions have not been reached, the concept of risk to individuals is well-defined and quantified. In particular, the quantity 'effective dose', E, affords an appropriate means of assessing detriment from generalized whole-body exposures, providing an estimate of the increased lifetime risk from cancers that is adequate for radiation protection purposes (ICRP, 2007). 
However, in fact, tissue reactions are the most clinically significant consequences of highdose exposures to ionizing radiation, and there is currently no universally recognized or recommended dose quantity that can be used to assess generalized risks to individuals following whole body exposures in the high-dose range. This is particularly problematic in emergency response situations, for example, following external exposures of large numbers of individuals: in attempts to relate the triage dosemeter absorbed dose to the risk to the individual, such that a 'dose' may subsequently be reported to medical professionals, it is necessary to first agree on the quantity to be reported.

Circumstances might arise in which large exposures to penetrating radiation are received by people who are not routinely monitored; examples could be members of the public present during a radiological or nuclear terrorist attack. In such cases it would be advantageous to use fortuitous dosemeters: objects that individuals might carry routinely about their person that, under the right conditions, can act as indicators of the dose received. The identification and characterization of fortuitous dosemeters is currently an active area of research with, for example, components within mobile phones being promising candidates (Trompier et al., 2017). However, one obvious limitation is that the dose received by the dosemeter could differ significantly from the dose to the individual, with the discrepancy strongly affected by the exposure conditions. For such a dosimetry system to be useful, it is therefore necessary to apply exposure-dependent conversion coefficients that relate the measured dose to the dose to the person. This is further complicated by the observation that it is unclear what dose quantity ought optimally to be converted to: whilst effective dose, in sieverts, is appropriate for stochastic risks at low doses, no analogous 'whole body' dose quantity is currently defined for exposures for which tissue reactions dominate.

A joint research project between EURADOS WGs 6 and 10 has been established to investigate these issues. The research splits into two interrelated work-streams: an investigation into the optimum 'whole body' dose quantity for quantifying risks to individuals receiving grays (rather than sieverts) of dose; and the generation of a database of conversion coefficients for relating mobile phone doses to doses to individuals, along with appropriate data management software. Both work-streams focus primarily on modelling of the doses received from photon exposures, which are considered the most relevant for realistic emergency scenarios. 
A joint WG6 and WG10 review paper (Eakins and Ainsbury, 2018a) was recently published, presenting a brief review of the likely scenarios and emergency dosimetry techniques that require such a quantity, before examining the biological constraints and requirements that might underpin any future definition. The requirements for emergency dosimetry are discussed in brief, focusing on the needs for doses greater than approximately 1 Gy (the ICRP 'threshold' dose for tissue reactions). The available retrospective dosimetry methods are outlined in brief, together with the current status of protection recommendations from ICRP. The issue of how to assess high doses is then approached from the perspective of the biological requirements, with consideration of the most serious tissue reactions in various exposure scenarios. The aim was to outline the arguments for developing a commonly agreed dose quantity for reporting high-dose radiation exposures in order to promote further discussion on this topic.

Monte Carlo modelling was then carried out using the Monte Carlo code MCNPX (Pelowitz, 2011), with organ doses assessed via the ICRP Reference Man voxel phantom. A range of exposure scenarios was investigated to explore when the differences between a number of candidate quantities (absorbed doses to the small intestine, the red bone marrow, brain, lungs, blood, teeth, gastrointestinal system, skin, several combinations of the above quantities, absorbed dose to the total body and air kerma) was most or least manifest and to investigate the patterns of factors that contribute to their relative performances. To generate dose conversion coefficients, simple representations of mobile phones were positioned at different locations around the voxel phantom, and the arrangement was subjected to various exposures in order to determine the ratios between the phone and organ doses. Exposures to $100 \mathrm{keV} \mathrm{X-}$ ray and ${ }^{192} \mathrm{Ir},{ }^{131} \mathrm{I},{ }^{137} \mathrm{Cs}$ and ${ }^{60} \mathrm{Co}$ radionuclide sources were considered, from seven different orientations (AP, PA, LLAT, RLAT, ISO, ROT and ground contamination).

The modelling suggested (Eakins and Ainsbury, 2018b) that the average (' $D_{G R B}$ ') of the absorbed doses to the stomach, small intestine, red bone marrow and brain was the optimum quantity for informing assessments of risk following large whole body exposures. Moreover a second, maximally conservative dose quantity (' $D_{M a x}$ ') was also proposed, with the intention of placing limits on any under-estimates resulting from the adoption of $D_{G R B}$. However, further work is still required to refine these suggested quantities, so for prospection the database of conversion coefficients lists results not only for $D_{G R B}$ and $D_{M a x}$, but also for three other candidate 'whole body' dose quantities as well as 28 individual organ doses; more than 
$\sim 17,000$ conversion coefficients have hence so far been produced. As an additional bonus, intra-database ratios can also be obtained using the results, such as between blood and $D_{G R B}$, which could find useful application in comparisons between biological assays. Results have also been obtained for isotropic point source positioned at a number of distances and locations relative to the body, and in support of field-test campaigns that allow calculated doses to be benchmarked against measured biodosimetric and physical data (Discher et al, 2019).

Although a promising start, future work will be needed to maintain relevance and to generate data for novel fortuitous dosemeters as they are developed, taking into account new methods and the expectation that new materials may be located differently about the body. Extensions to other exposure conditions, and the inclusion of neutron dosimetry, may also be required.

\subsection{Assessing the contribution of cross-sections to the uncertainty of Monte Carlo calculations in micro- and nano-dosimetry}

Working Group 6 brings together scientists interested in researching the links between the micro- and nanodosimetric characterization of energy deposition and radiation-induced biological effects. Indeed, Monte Carlo (MC) simulation techniques are often used to study particle track structure in different target volumes to find the correlations with biological effects of different radiation qualities. To this end, dedicated track-structure MC codes have been developed and some general-purpose MC codes have recently been upgraded to enable the simulation of energy depositions in micrometric or nanometric volumes. These MC codes include different cross-section data tables or models and computed results are known to strongly depend on the cross-section data used to describe the individual inelastic interactions of charged particles, in particular electrons of very low energy. Therefore an estimation was needed of the uncertainty in microdosimetric spectra or frequency distributions of ionizations in nanometric volumes due to the use of different cross-section data in MC codes.

To estimate this uncertainty, WG6 launched a two-step exercise in 2017. In the first step, participants using different $\mathrm{MC}$ codes were asked to calculate microdosimetric spectra in a 10 $\mu \mathrm{m}$ diameter water sphere using an electron source spectrum corresponding to a mean decay of ${ }^{125} \mathrm{I}$ (Howell, 1992) and three geometrical configurations. Besides, and for those participants using track structure codes, ionization cluster size distributions (ICSDs) in $3 \mathrm{~nm}$ 
and $8 \mathrm{~nm}$ diameter target spheres at different distances from the source were also requested. ICSDs correspond to the probability distribution of the number of ionisations taking place in a nanometric volume and are a typical measurable quantity in experimental nanodosimetry.

Preliminary results of the first part of the exercise have been recently published (Villagrasa et al., 2019). For the microdosimetric calculations nine participants using different MC codes (general purpose and track structure codes) sent their results for the three configurations. The form and mean values of the specific energy distribution spectra were in quite good agreement for the point and volumetric source, independently of the implemented crosssections and cut-off energy used for electron transport. In the case of a surface-source distribution, only track structure codes show a relatively good agreement and the cut-off energy used in general purpose MC codes seems to have an impact in the transport of the very low energy electrons emitted by the source.

Concerning the nanodosimetric calculations, ICSDs of different track structure codes were compared. In particular, the Geant4-DNA MC code was run with several "physics lists", which corresponds to different physical models for the electron transport. Thus, WG6 was able to estimate the impact of using different cross-sections for electrons while keeping the same MC transport method. In general, the differences in the ICSDs results were large and mean values differed up to $40 \%$.

A preliminary sensitivity analysis could also be performed with Geant4-DNA: total interactions cross-sections from a given physical model were changed by $10 \%$ up to a factor of 2 . The preliminary results indicated that interaction cross-sections for low-energy electron interactions may have associated uncertainties in the order of $100 \%$.

The objective of this first exercise was to estimate the dispersion of different results in both microdosimetric and nanodosimetric calculations and determine an uncertainty budget. The second part of the exercise will be announced at the beginning of 2020. Then, this uncertainty budget will be used to modify the electron cross-sections in track structure codes and compare the results with those of modified codes.

\subsection{Simulation of a Linac using different Monte Carlo codes}


In radiotherapy, Monte Carlo (MC) methods are considered a gold standard to calculate accurate dose distributions, particularly in inhomogeneous tissues. Accordingly, WG6 organized an international comparison applying different MC models to a real medical linear accelerator. The comparison focused on relative dose distributions in both a homogeneous water phantom and four different inhomogeneous phantoms for a nominal 12-MV photon beam. The results of the comparison allowed to study the sensitivity of the computed depthdose curves and dose profiles to variation of the parameters of the accelerated electron beam (parameters whose actual values in a given accelerator are often known only approximately) giving rise to the photon therapeutic beam. This is relevant for the reliability of the computed dose profiles for concrete therapeutic interventions, each one involving the irradiation of a different inhomogeneous volume. After adjustment of the parameters to match as close as possible the experimentally obtained depth-dose curve and dose profile in a homogeneous water phantom, the participants in the comparison were asked to provide the result (again concerning depth-dose curves and dose profiles at given depths) for four different inhomogeneous phantoms, each one having lung-equivalent tissue slabs and/or boneequivalent tissue slabs. In Fig. 11 an overall view of the local dose differences for the depthdose curve in the water phantom for the six different participants is given.

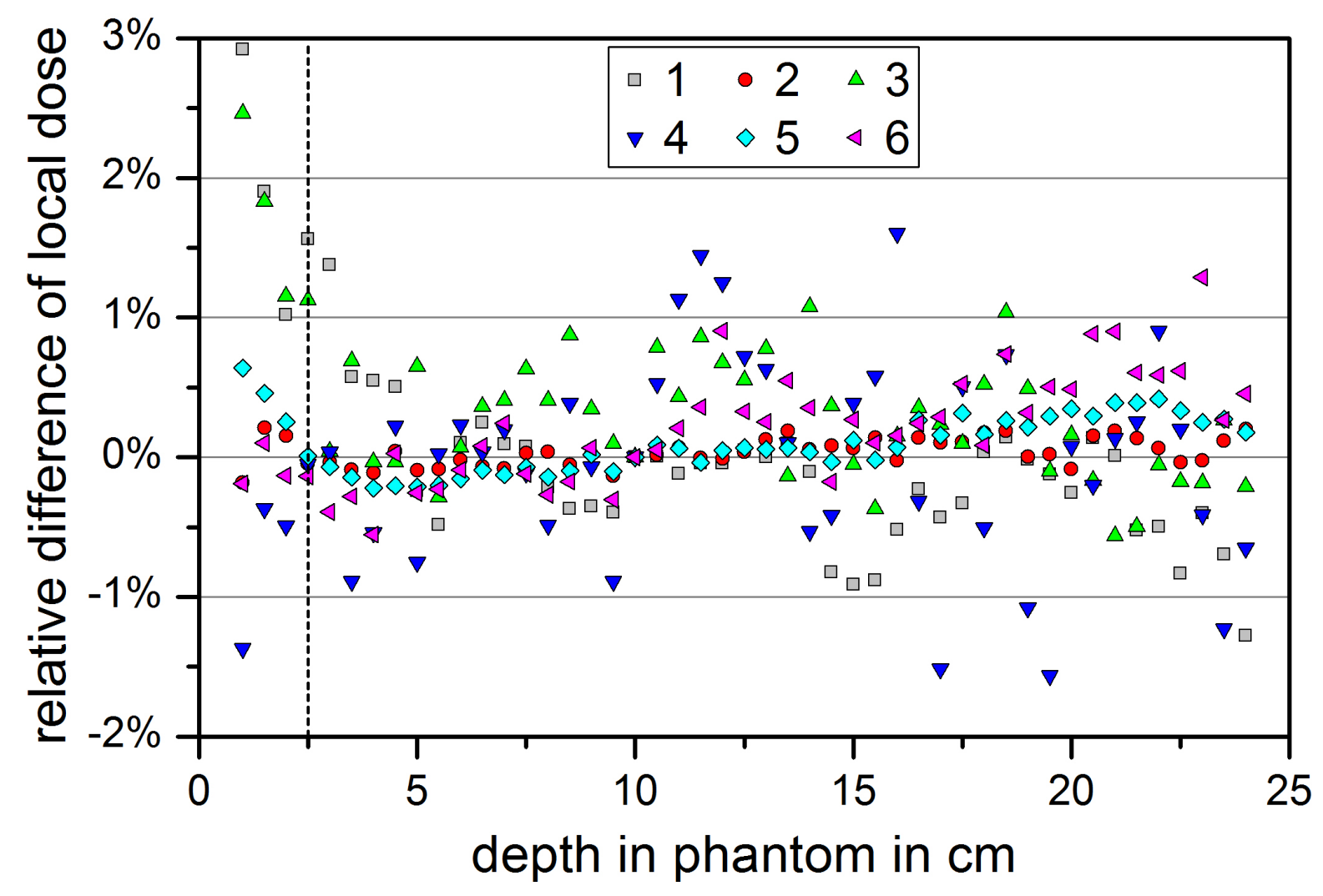


Fig. 11. Dose differences calculated by means of MC simulation (six different participants) against experimental depth dose curve for a homogeneous water phantom. The vertical dotted line indicates the depth of the build-up for the considered beam.

In conclusion, critical aspects useful for MC users to build and calibrate a simulation of a medical linear accelerator and perform a dosimetric analysis were identified. Results were made widely available through their publication in open access mode and the complete experimental dataset assembled for this comparison was made available on request to all the MC users, thus providing them an opportunity to build and calibrate a model for a real medical linear accelerator with real dosimetric data.

\section{WG 7 "Internal Dosimetry"}

Internal dosimetry for humans after incorporation of radioactivity is a challenging task, because measurements of the committed doses are not possible. Therefore, measurements of activities retained in the body (in-vivo monitoring) or in the excretions of the body (in-vitro monitoring of urine and feces) are performed in certain times after the intake. Doses due to internal exposures are then calculated from the measured activities using biokinetic and dosimetric models. The former describe the metabolic behavior of the radionuclides of interest in the body and provide information about their retention in and excretion from the body. In contrast, the latter describe the energy deposition following the decay of the radionuclides and their progeny. The whole process of dose assessment includes many sources of uncertainties. For example, the pathway (inhalation, ingestion, incorporation through a wound, or a combination of these) and timing of the incorporation is often not exactly known, the chemical form of the incorporated substances is unclear, its biokinetic behavior within the human body is not exactly defined and may be subject to individual variability. Structured approaches for the planning of suitable monitoring programs and the interpretation of the monitoring data have been developed to provide guidance to the assessors and thus to reduce the uncertainties arising from different procedures and assumptions applied in the calculations (Castellani et al 2013, EC RP 188). 
EURADOS WG7 is tackling the topic internal dosimetry by looking at all the different aspects involved in dose assessment ranging from planning of monitoring programs, measurement techniques, models involved, uncertainties and structured approaches to dose assessment. WG7 is focusing on the dose assessment for occupational internal exposures but is also putting attention on emergency situations involving public exposures e.g. for epidemiological studies (Davesne et al 2018). Microdosimetry of internal emitters (Hofmann et al. 2019, Li et al. 2019) is another research topic studied by the group that requires computational techniques.

\subsection{Measurements and Monte Carlo simulations for the calibration of in-vivo counters}

In vivo monitoring techniques are used for direct measurements of radionuclides incorporated and retained in the body and for the assessment of the associated committed doses. The whole-body or partial body counters used require a thorough calibration that takes into account as closely as possible human anatomy. In order to obtain calibration factors that permit quantification of activity in a contaminated person, anthropomorphic or anthropometric phantoms are often used when available, being designed and fabricated as realistically as possible. Intercomparisons involving in-vivo measurements have been organized by EURADOS together with partners for example from the Lawrence Livermore National Laboratory (LLNL) for thyroid counting (Hickman et al. 2018) and with the United States Transuranium and Uranium Registries (USTUR) for knee and skull counting (Lopez et al. 2011, Nogueira et al. 2015, Lopez et al. 2019). An alternative to such calibrations using physical phantoms are Monte Carlo (MC) simulations using detector and human-body models (e.g. voxel models). In the last years WG7 organized, in collaboration with WG6, several intercomparison exercises for the Monte Carlo calibration of partial counters in lung geometry (Broggio et al. 2015), knee geometry (Lopez et al. 2011) and skull geometry (Lopez et al. 2019, Vrba et al. 2014, Vrba et al. 2015). The main objectives were: (1) to check the skills of dosimetrists using Monte Carlo methods for simulating the whole in vivo detection process, (2) to compare available physical phantoms with computational phantoms (e.g. produced from real CT images of patients) to evaluate the usefulness of the available physical phantoms and (3) to compare measured and simulated spectra in various geometries. For the dissemination of appropriate MC techniques, specific hands-on training courses on application and calibration of in-vivo counters have been organized by WG7 in 2013 
(Breustedt et al. 2016) and more recently in 2018. All these WG7 actions supported the use of MC methods for the calibration of body counters when the detector model is well known. Furthermore, it turned out that computational phantoms allow for a more realistic representation of any individual differences in body size (depending in turn on sex and age) than any existing physical phantom.

In a recent study WG7 has- in collaboration with USTUR - used three available anthropomorphic skull phantoms contaminated with ${ }^{241} \mathrm{Am}$, a bone-seeking radionuclide, to study their use in retrospective dose assessment after incorporation of ${ }^{241} \mathrm{Am}$ (Lopez et al. 2019). The three phantoms were a) from a body donation of an individual who had been accidentally contaminated, b) a human skull artificially contaminated with ${ }^{241} \mathrm{Am}$ on the outer and inner surface of the skull, and c) an artificially fabricated simple hemisphere of equivalent bone and tissue material contaminated with ${ }^{241} \mathrm{Am}$. Ten dosimetry laboratories from Europe and two from North America participated in the study. The participants were asked to measure the counting efficiency using the three phantoms with a germanium detector, and the ${ }^{241} \mathrm{Am}$ in the three skulls using their own calibration procedures (Nogueira et al. 2015). In a parallel exercise, a Monte Carlo simulation of the three skull phantoms was performed by 16 participants including simulation of the counting efficiency of one predefined germanium detector using the artificial voxelized skull phantom, the counting efficiency of a detector used in the participating laboratories for the three anthropomorphic skull phantoms, and a MC simulation of the whole detection process used in the participating laboratories with as many detectors as feasible (Vrba et al. 2014, 2015).

The overall conclusion of this combined international effort including calibration measurements and MC simulations was that "none of the three available physical skull phantoms is appropriate as a reference for the calibration of germanium systems used to measure ${ }^{241} \mathrm{Am}$ in exposed adult individuals". This is the case because a) in an accidental incorporation the ${ }^{241} \mathrm{Am}$ distribution within the skull bone (one of the used phantoms) is unknown but probably not homogenous, and b) the geometries of the other two available phantoms were not judged representative to match size and shape of a typical adult skull. However, it was found that MC simulations offer a better alternative for calibrating partial body counters in skull geometry than measurements, in particular if individual data on skull geometry of the contaminated person are available, which could be used in the MC process to simulate individual calibration factors. 


\subsection{Biokinetic modeling}

Biokinetic models are used to mathematically describe the behavior of radionuclides in the human body. The International Commission on Radiological Protection (ICRP) develops reference models, whose solutions (i.e. retention and excretion functions) are applied in the dose assessment process. All of these models assume an unperturbed behavior of the radionuclide within the human body. In the case of incorporation of high levels of activities, decorporation therapy is applied to enhance the excretion of certain radionuclides and to reduce their retention in the body and, thus, the associated committed dose. In such a case, the ICRP reference models can no longer be used. Instead, a biokinetic model which takes into account the effects of the therapy is required for a proper dose assessment and the evaluation of the therapy efficacy. Additionally, such a model can be used to optimize the therapy protocol.

Within the CONRAD project (Lopez et al, 2008) EURADOS initiated the development of a model describing the biokinetics of actinides following decorporation therapy with DTPA (Breustedt et al. 2009). The current model used by WG7 includes three separate compartmental models describing the behavior of a) the actinide, b) the injected forms of DTPA and c) the complexes of actinide and DTPA formed in-vivo. The in-vivo chelation process is modeled by transferring material from a) to c) using a second order process with a chelation constant KR. Models b) and c) are based on a physiological interpretation of data given by (Stather et al. 1983). Kastl (Kastl et al. 2014) described a revision and physiological interpretation of model a) based on animal experiments. The model and variations of it were refined using artificial scenarios and successfully applied to study several real contamination cases (Breustedt et al. 2019).

It is concluded that this approach is a promising way towards a generic model of decorporation therapy. Physiological understanding of the processes involved and an according interpretation of the compartmental systems is required for the future modelling and optimization of decorporation therapy by DTPA.

\subsection{Uncertainties in internal dosimetry}


Sources of uncertainties in calculated doses include the uncertainties of the model parameters and the assumptions (e.g. choice of models, route of intake, ...) made during the assessment. A study of the cesium biokinetic model performed by WG7 is described in Li et al. 2015. The model used was derived by Leggett (2003) using a blood flow model and fractions of cardiac output which enters the different organ compartments. Factors contributing to the uncertainties in individual model parameters were identified by studying the physiological basis the parameter values were derived from. Standard deviations, uncertainty factors (UFs), partial rank correlation coefficients and coefficients of variation were used to quantify the uncertainties arising from the uncertainties of the model's parameters, which all are mainly due to inter-individual variability. The different available codes and techniques applied for the calculation of uncertainties gave similar numerical results. UF values for retention in blood, retention in whole body and urinary excretion, increased from a value of less than 2 (for times less than $100 \mathrm{~d}$ after incorporation) up to 20 (at day 500) and $>40$ (day 1,000). For whole body retention, data from several studies were available and could be described by the confidence interval that was calculated in the study. Li and coauthors also investigated the sensitivity of single parameters on the retention in blood and whole body and the urinary excretion. Transfer rates between muscle and blood, kidneys and blood and the transfer rate from kidney to urinary bladder contents turned out to be influential parameters in the biokinetic model of cesium. This information is important when adapting the reference model to an individual model. Furthermore, the knowledge of uncertainties in biokinetic models can be propagated to uncertainties in dose coefficients.

It should be emphasized that the uncertainties in dose assessment are important for epidemiological studies, which link health effects to radiation exposure. For studies on uranium miners, lifetime doses need to be estimated (Davesne et al. 2018). Consequently, WG7 organized an intercomparison to compare dose assessment protocols applied by different participants, to identify sources of uncertainty, and to discuss the assessment of uncertainty on dose (Davesne et al. 2017). Three cases with different exposure scenarios were presented to the 16 participants, who should then calculate the committed equivalent doses to lungs and kidneys and the committed effective dose, due to uranium intake. The ratios of maximum to minimum values of the assessed doses turned out to be much higher than the factor of 3 usually acknowledged by experts to be acceptable for internal dosimetry. Interestingly, the kidney equivalent dose was less sensitive to uncertainty because doses were estimated mostly from urine data, which are strongly correlated to the systemic doses. This 
work will be used as a basis for defining guidelines to reconstruct lifetime doses after intake of uranium, for epidemiological studies and for compensation claims.

\subsection{Dose Assessment Methodology}

Another major source of uncertainty includes the set of assumptions used by the assessors, especially if a series of measurements has to be evaluated. Members of WG7 have developed and revised guidelines for a structured approach to dose assessment (Castellani et al. 2013). Recently, these guidelines have been implemented in the "Technical Recommendations for Monitoring Individuals for Occupational Intakes of Radionuclides" that were developed by WG7 members for the European Commission (EC 2019). The application of this methodology was successfully tested in the ICIDOSE intercomparison exercise (Castellani et al. 2019).

\subsection{Internal dosimetry in emergency situations}

In case of radiological and nuclear emergencies involving incorporated radionuclides the priority is to identify individuals at highest contamination level (triage) and rapidly estimate the associated doses; this will help decision makers in a proper management of the accident situation. A reliable quantification of associated internal exposures to contaminated organs and tissues also permits a proper design of epidemiology studies and risk assessment. In this context, WG7 members have been involved in different actions and research projects collaborating also with WG10 in the on-going EC CONFIDENCE Project "Coping with Uncertainties for Improved Modelling and Decision Making in Nuclear Emergencies".. Another current WG10-WG7 collaboration is dealing with a review on retrospective dosimetry techniques for internal exposures to ionizing radiation and their applications (Giussani el al., 2019).

Regarding in vivo monitoring of incorporated radionuclides in case of nuclear emergencies, after the Fukushima Daiichi NPP accident important gaps were identified in the measurement of radioiodine in thyroids of exposed individuals. Members of WG7 prepared and participated in the EC-funded CAThyMARA project on "Child and Adult Thyroid Monitoring After Reactor Accident”. Aim of this project was to establish post-accidental 
monitoring strategies and guidelines for proper assessment of thyroid doses in children and adults resulting from intakes of radioiodine. This led to recommendations for a better detector calibration, improved measurement and dose assessment capabilities and formulation of technical guidelines to harmonize European emergency response strategies.

Finally, an intercomparison bioassay exercise was organized by WG7 in 2014 (Li et al., 2014) whose main outcomes were the development and implementation of in vitro bioassay methods resulting in shortened times required for the analysis of urine samples of individuals contaminated in a nuclear emergency frame, which also permit a faster dose evaluation in intake scenarios involving alpha and beta emitters.

\section{WG9 "Dosimetry in Radiotherapy"}

Out-of-field doses in radiotherapy have been increasingly studied in recent years because of the risks of second cancer induction in patients who may, with the benefits of modern treatment techniques and consequent improved prognoses, have longer life-expectancies. Radiotherapy has undergone an impressive expansion in recent years with the emergence of intensity modulated radiotherapy (IMRT), image guided radiotherapy (IGRT), proton and ion beam facilities. Proton radiotherapy in particular offers improved capabilities for target coverage with minimal normal tissue irradiation but is accompanied by additional neutron production compared with traditional photon techniques. Consequently, there is a need to develop dosimetry techniques which can be used to provide robust dose information for epidemiological studies as well as for patient safety and the more general study of the radiation effects on humans.

The following covers dosimetry in photon and proton radiotherapy, using water tank and anthropomorphic phantoms and a variety of active and passive detectors used within phantoms and in the vicinity of the treatment machine and the patient. In order to address critical patient groups, this work has largely been directed towards paediatric radiotherapy.

\subsection{Out-of-field dosimetry in photon radiotherapy}

The two studies in photon radiotherapy described below address the treatment of children for brain lesions (tumour and arteriovenous malformations (AVM)) and compare IMRT, 3D conformal radiotherapy (3D CRT) and GammaKnife $\left.{ }^{(G K}\right)$ radiotherapy. 
In the first study, out-of-field doses were measured in anthropomorphic paediatric phantoms which received a simulated treatment of a brain tumor with IMRT and 3D CRT (Majer et al., 2017). Organ doses were measured in critical organs with radiophotoluminescent (RPL) and thermoluminescent (TL) dosemeters in $5 \mathrm{y}$ old and $10 \mathrm{y}$ old anthropomorphic phantoms. Results showed that, for IMRT, doses for the $5 \mathrm{y}$ phantom were on average 1.6 times higher than those for the $10 \mathrm{y}$ phantom. For $3 \mathrm{D}$ CRT, doses for the $5 \mathrm{y}$ phantom were higher than those for the $10 \mathrm{y}$ phantom by a factor of 3 . This was attributed to the use of a mechanical wedge for the treatment of the 5 y 3D CRT phantom. Due to different configurations of the radiation fields, for both phantoms, the IMRT technique resulted in a higher non-target brain dose and higher eye doses but lower thyroid doses compared to 3D CRT. For 3D CRT (which used a non-coplanar field configuration), eye doses were $3-6 \%$ of the treatment dose for IMRT (which used a coplanar field configuration) and $27-30 \%$ of the treatment dose for 3D CRT. For the thyroid and more distant organs, doses were less than $1 \%$ of the treatment dose. A potentially important finding was that a comparison of measured doses and doses calculated by the treatment planning system (TPS) showed that the TPS underestimated outof-field doses both for IMRT and 3D CRT. It should be noted that, for both IMRT and 3D CRT, out-of-field dose values are specific to the investigated case, the phantoms used and the treatment planning principles employed at the centers where this work was carried out. Nevertheless, these results provide useful information for benchmarking existing or future models (Schneider et al. 2017) and emphasize the importance of out-of-field doses in paediatric radiotherapy.

The second study compares out-of-field doses in children treated for large arteriovenous malformations (AVMs) using hypofractionated GK radiosurgery and IMRT (De Saint-Hubert et al., 2018). This study employed similar materials and methods to Majer et al (2017), in that out-of-field organ doses in two anthropomorphic child phantoms (5 y and $10 \mathrm{y}$ ) were measured, using RPL, TL and optically stimulated luminescence (OSL). The target volume was identical in size and shape in all cases. Good agreement within 1-2\% between dosimetry types (RPL and TL) was shown. The number of GK isocentres was confirmed to be important for the magnitude of out-of-field doses when using this technique. Measured GK doses for the same distance from the target, when expressed per target dose and isocentre, were comparable in both phantoms. GK out-of-field doses averaged for both phantoms were evaluated as $120 \mathrm{mGy} / \mathrm{Gy}$ for the eyes, reducing to $20 \mathrm{mGy} / \mathrm{Gy}$ for the mandible and up to $0.8 \mathrm{mGy} / \mathrm{Gy}$ for the testes. Taking into account the fractionation regimen used to treat AVM 
patients, the total doses to the out-of-field organs were calculated and compared with IMRT. The eyes were better spared with GK whilst more distant organ doses were up to a factor of 2.8 and 4 times larger for GK compared to IMRT in the $5 \mathrm{y}$ and $10 \mathrm{y}$ old phantoms, respectively. As in the study of Majer et al. (2017), out-of-field dose values are specific to the treatment and dosimetry parameters chosen, but again emphasize the complexity of the problem for individual patients and illustrate the wide range of parameters which can influence out-of-field doses and the consequent risk of second malignancies.

\subsection{Out-of-field dosimetry in proton radiotherapy}

In the case of proton radiotherapy, unwanted doses from secondary radiation including a mixed spectrum of secondary neutrons, secondary and prompt gammas, as well as scattered and secondary charged particles, depends on the treatment unit design and shielding and also on the treatment room layout itself. For double or single scattering techniques, a significant stray radiation component is produced in the beam formation elements. In scanning therapy units with a dedicated nozzle, most of the secondary radiation is generated in proton interactions with the phantom or body.

EURADOS Working Group 9 performed a comprehensive experimental and Monte Carlo characterization of out-of-field doses in spot scanning proton therapy. This project included measurements of out-of-field neutron and photon doses inside a water phantom and inside paediatric anthropomorphic phantoms as well as mapping stray radiation around the patient with active detectors and Bonner Spheres. Moreover, an intercomparison of different types of passive and active detectors in a secondary radiation field produced in commercially available spot scanning proton therapy facilities was performed.

Stolarczyk et al. (Stolarczyk et al. 2018) characterized unwanted doses from secondary neutrons and gamma radiation produced by a $100 \times 100 \times 100 \mathrm{~mm}^{3}$ scanning proton beam in a $300 \times 300 \times 600 \mathrm{~mm}^{3}$ water phantom. For in-phantom measurements, passive detectors including polyallyldiglycol carbonate (PADC)-based $\left(\mathrm{C}_{12} \mathrm{H}_{18} \mathrm{O}_{7}\right)$ track-etched detectors, thermoluminescence detectors (TLDs): MTS-7 ( $\left.{ }^{7} \mathrm{LiF}: \mathrm{Mg}, \mathrm{Ti}\right), \mathrm{MTS}-6\left({ }^{6} \mathrm{LiF}: \mathrm{Mg}, \mathrm{Ti}\right), \mathrm{MTS}-\mathrm{N}$ ( $\left.{ }^{\text {nat }} \mathrm{LiF}: \mathrm{Mg}, \mathrm{Ti}\right)$ and TLD-700 ( $\left.{ }^{7} \mathrm{LiF}: \mathrm{Mg}, \mathrm{Ti}\right)$ and radiophotoluminescent (RPL) detectors GD$352 \mathrm{M}$ and GD-302M were used. The doses from secondary photons measured in a direction perpendicular to the primary beam were at the level of $0.2 \mathrm{mGy} / \mathrm{Gy}$ at a distance of $100 \mathrm{~mm}$ and $0.03 \mathrm{mGy} / \mathrm{Gy} 300 \mathrm{~mm}$ from the isocenter (data from TL MTS-7 detectors from Institute 
of Nuclear Physics (IFJ PAN), Poland). Secondary neutron dose equivalents at corresponding positions were approximately equal $\sim 1.5 \mathrm{mSv} / \mathrm{Gy}$ and $\sim 0.06 \mathrm{mSv} / \mathrm{Gy}$ (data from PADC track detectors from Universitat Autònoma de Barcelona (UAB), Spain), respectively (Fig. 12). One of the important conclusions from this work comes from a comparison of out-of-field doses in spot scanning proton radiotherapy and $20 \mathrm{MV}$ X-rays. Both experiments were performed in an identical set-up, using the same types of detectors and target size. Surprisingly, neutron doses were comparable for photon and proton treatment, while out-offield photon doses for the scanning proton beam were on average $10^{2}$ times lower than in case of $10 \times 10 \mathrm{~cm}^{2}$ box treatment with $20 \mathrm{MV}$ X-rays.

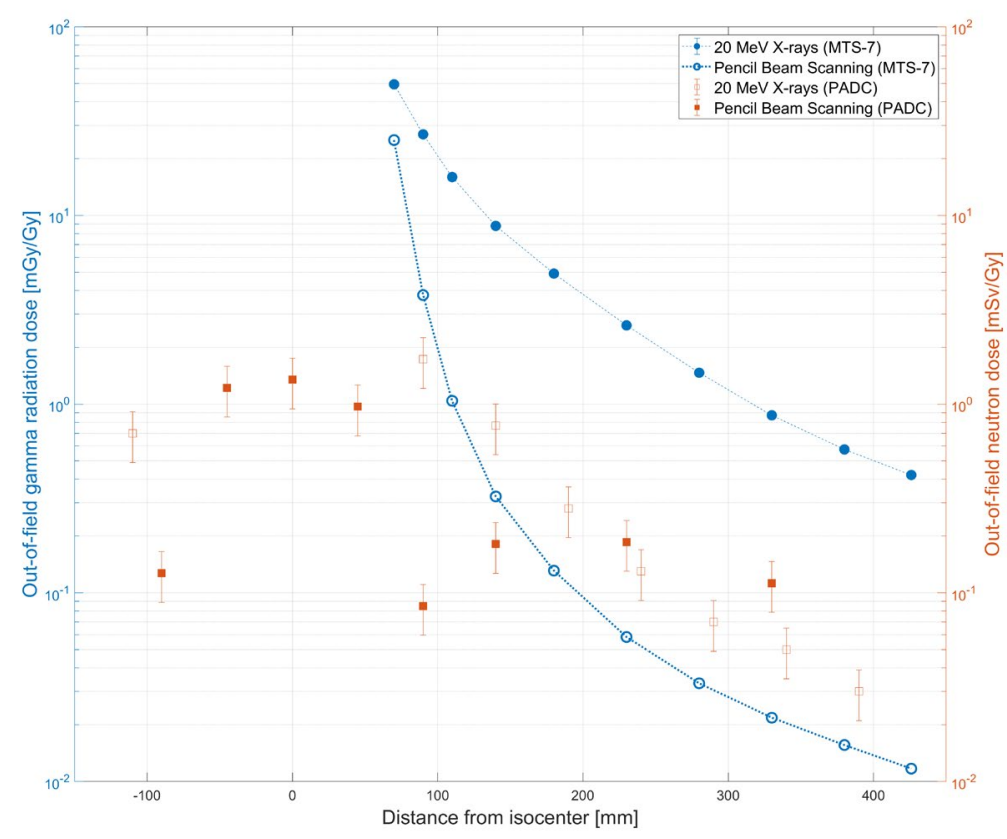

Fig. 12. Out-of-field neutron and gamma doses measured in $30 \times 30 \times 60 \mathrm{~cm}$ water phantom with PADC track detectors (UAB, Universitat Autònoma de Barcelona, Spain) and TL detectors type MTS-7 (MTS-7) (Institute of Nuclear Physics (IFJ PAN), Poland) for single field $20 \mathrm{MeV}$ X-ray radiotherapy (field size $10 \times 10 \mathrm{~cm}$ ) and proton pencil beam scanning technique for $10 \mathrm{~cm} \times 10 \mathrm{~cm} \times 10 \mathrm{~cm}$ field with range $20 \mathrm{~cm}$ and modulation width $10 \mathrm{~cm}$.

The response of different passive dosimetry systems in the mixed secondary radiation field of spot scanning proton radiotherapy was compared not only in a simplified geometry of a water phantom (Stolarczyk et al. 2018), but also for realistic clinical irradiations of anthropomorphic phantoms (5 and 10 year old) (Knežević et al. 2018). It was shown that the 
signal from protons scattered from the primary beam (proton beam halo) has a significant impact on both RPL and TL signal in the proximity of the target. Moreover, in a mixed neutron and gamma radiation field, TL detectors type $\mathrm{LiF}: \mathrm{Mg}$, Ti with ${ }^{7} \mathrm{Li}$ measured not only photon dose, but also a non-negligible signal (at the level of a few percent) from secondary neutrons. The contribution of secondary neutrons to the total TL signal depends strongly on neutron energy spectra and varies at different positions inside the phantom with respect to the proton field. On the other hand, RPL detectors showed lower sensitivity to neutrons. Results from track detectors and bubble detectors, based on two separate methods using either (i) neutron fluence or (ii) the relationship between track parameters and particle Linear Energy Transfer (LET), were found to be within measurement uncertainty.

A series of experiments was performed to map secondary radiation field inside and in the proximity of the gantry room with a dedicated scanning nozzle. Firstly, Farah et al. (Farah et al. 2015) compared active dosimetry systems in the mixed neutron and gamma radiation field in proton spot scanning radiotherapy. $H^{*}(10)$ measurements were performed around a $300 \times 300 \times 600 \mathrm{~mm}^{3}$ water phantom at eight positions inside and three positions outside the gantry using rem-counters (a regular and an extended-range NM2B, LB 6411, RadEye ${ }^{\mathrm{TM}}$ NL and WENDI-II) and TEPC-tissue equivalent proportional counters (Hawk type). It was observed that conventional rem-counters underestimated neutron $\mathrm{H}^{*}(10)$ up to a factor of 4 , while the Hawk TEPCs and WENDI-II extended-range rem-counter were found to have good agreement (within 20\%) even at the points with the highest neutron fluence and energy. $H^{*}(10)$ values decreased significantly with distance and angular position with respect to the beam axis. The influence of proton beam parameters on the secondary radiation doses was investigated in a separate experimental campaign using active detectors positioned around $300 \times 300 \times 600 \mathrm{~mm}^{3}$ solid water phantom (Mojżeszek et al. 2017). The dependence of $\mathrm{H}^{*}(10)$ on proton beam energies between 100 and $220 \mathrm{MeV}$, field sizes from $2 \times 2$ to $20 \times 20$ $\mathrm{cm}^{2}$ and modulation widths from 0 to $15 \mathrm{~cm}$ was verified. Large variations in out-of-field neutron doses were observed with primary beam energy and field size, while changes of modulation were shown to be less important. The maximum $\mathrm{H}^{*}(10)$ value of $72.3 \mu \mathrm{Sv} / \mathrm{Gy}$ was measured for $200 \mathrm{MeV}$ proton beam with $20 \times 20 \mathrm{~cm}^{2}$ field size at point $1 \mathrm{~m}$ from isocenter along the beam axis.

A dedicated experiment was organised for microdosimetric spectra measurements around a paediatric phantom (Farah et al. 2017). Four different tissue-equivalent proportional counters 
(TEPC), first compared in standard neutron and gamma radiation fields, were used. The largest contribution from low-LET particles was observed at $90^{\circ}$ with respect to the beam axis, whereas high-LET particles were registered mostly at smaller angles.

In addition, two extended-range Bonner sphere spectrometry (BSS) systems were used to determine the neutron spectra both in the presence of the water phantom (Farah et al. 2015) and also for realistic clinical scenario (Mares et al. 2016). The thermal part of the spectrum did not change significantly with the position around the phantom. Conversely, the component from high energy neutrons was measurable only in proximity to the primary beam axis and varied strongly with angle from the main axis. For example, at $329^{\circ}$ to the beam axis and $1.63 \mathrm{~m}$ from the isocenter, neutrons with energies above $20 \mathrm{MeV}$ were about $50 \%$ of the total $\mathrm{H}^{*}(10)$ value of $2.7 \mu \mathrm{Sv} / \mathrm{Gy}$.

These comprehensive studies of neutron energy spectra and microdosimetric spectra, environmental and in-phantom doses are of great value not only for the protection of patients undergoing radiotherapy or personnel working in proton radiotherapy centres, but also for benchmarking analytical and Monte Carlo models of secondary radiation fields. The development of such models will be important for the comprehensive determination of the complete patient dose on a routine basis.

\section{WG10 - "Retrospective Dosimetry"}

\subsection{Methods and Uncertainty in Biological and Physical Retrospective Dosimetry}

Biological and retrospective physical dosimetry are recognised to play a crucial role in rapid assessment of dose following a radiological accident or incident and the state of the art is represented by a number of different assays (e.g. Kulka and Wojcik, 2017 and papers therein; Bailiff et al. 2016). The need for a wide range of techniques, which can be used both separately and in conjunction, is clearly documented, in order that accurate dose estimation can be achieved in different exposure scenarios. The state of the art in terms of operational assays has recently been amalgamated into functional emergency response plans through the RENEB (Running the European network of biological and retrospective physical dosimetry) network (Kulka and Wojcik, 2017). 
The objective of EURADOS Working Group 10 (WG10) is to establish cooperation between European (and some non-European) laboratories with expertise in the areas of physical retrospective and biological dosimetry, in order that research underpinning provision of these dosimetry techniques is carried out in a collaborative manner. The aims of WG10 include: establishing multiparameter approaches to dose assessment in retrospective dosimetry (including emergency response); concerted evaluation of newly developed dosimetry methods, and establishing shared approachs for uncertainty estimation throughout biological and physical methods of dosimetry.

Interlaboratory comparisons are key to addressing the development of a multiassay approach to retrospective dosimetry. In 2017, a joint RENEB and EURADOS WG10 intercomparison took place, focusing on integration of new biological and physical retrospective dosimetry methods into EU emergency response plans (Ainsbury et al., 2017). Participants from approximately 30 (chiefly EU) countries contributed to dose estimation using the standard dicentric assay (DCA) and the dicentricy assay with centromere and telomere staining (DCATC), the gene expression assay (GE), raman spectroscopy (RS) on blood lymphocytes, and detection of radiation-induced thermoluminescence signals in glass displays taken from smart phones (TL). The specific aim of the intercomparison was to test the performance of newer techniques against the benchmark of the dicentric assay in a quality controlled dosimetry exercise. For the biological assays, blood was irradiated with ${ }^{60} \mathrm{Co}$ gamma rays at $0.7 \mathrm{~Gy}$ min $^{-}$ 1 to doses of $0,0.44,1.08$ and 1.89 Gy. Then either blood or cytogenetic images were distributed to partners for analysis. For GE and RS, calibration samples were also sent to allow formation of calibration curves. For TL measurements on display glass, a training was carried out at HMGU, prior to the intercomparison, so that participants could get familiar with sample preparation and the measurement technique. Mobile phone samples, equipped with TLDs (LiF) and pieces of annealed reference glasses taped to the screen, were then irradiated at IRSN using a 4MV linear accelerator. Each participating laboratory received three phone samples, irradiated with the nominal air kerma values of $0.6,1.5$ and $2.5 \mathrm{~Gy}$, respectively. Overall the results were very encouraging - for the most part, all partners were able to correctly identify doses within a level of uncertainty acceptable for emergency dosimetry scenarios (the 95\% confidential interval (CI) of the test dose), and thus all the 'new' methods were considered to be validated in comparison to the 'gold standard' dicentric assay, for the exposure conditions described. However, much work remains to be done in order to fully integrate the new assays into the established set of techniques available for 
retrospective dosimetry. As previously, the results clearly indicated the need for each laboratory to form their own calibration curve, and further attention should be paid to practical considerations including sensitivity and specificity, time scale for availability of results, standardisation and training. Nevertheless, the benefits of multi-parametric retrospective dosimetry techniques are clear.

Uncertainty analysis is the study of methods of quantification of the degree of confidence considering research model outputs, taking into account the model inputs (i.e. the data and parameters) (Helton, 2008). Accurate uncertainty assessment is an intrinsic part of scientific research, not least within retrospective radiation dosimetry where the uncertainties, especially in an emergency response scenario, can be very large. However, it has previously been noted that in some cases estimation approaches vary between different biological and physical retrospective dosimetry techniques and that the overall effort devoted to uncertainty analysis varies widely between groups of retrospective dosimetry practitioners (Ainsbury et al., 2017). In order to address the clear scientific need to advance high quality techniques for uncertainty estimation, WG10 task group 10.6 was created. In 2018, a manuscript was published summarising the current state of the art in uncertainty analysis for all the retrospective dosimetry techniques employed by members of WG10 (Ainsbury et al., 2018). The status quo was assessed through a questionnaire designed to gather information on current experience related to uncertainty estimation and also to assess the possible needs in terms of training or courses, which was sent to all members of WG10. The biological and physical techniques themselves are briefly described, and this is followed by a clear description of the uncertainty analysis methods currently recommended in the international standards, and discussion and promotion of the use of Monte Carlo and relevant Bayesian techniques to support characterisation of uncertainties. It was concluded that adequate techniques for uncertainty assessment are available and in use by most laboratories, but further work will be required to ensure that statistical analysis is always wholly sufficient especially for complex (e.g. highly inhomogeneous) exposure scenarios. Subsequently, two CONCERT training schools on EURADOS-CONCERT School on "Uncertainty in Biological, Physical and Internal Dosimetry Following a Single Exposure" have taken place in 2017 and 2019, in order to further disseminate the joint WG10 position on uncertainty analysis techniques for biological and physical retrospective dosimetry. Future work on development of uncertainty analysis techniques within this field will focus on standardisation of techniques and validation of different methodologies in a variety of exposure scenarios. Going forward, WG10 will 
continue to support development of new and improved uncertainty assessment techniques, together with appropriate training and dissemination.

\section{WG11 "High-Energy Radiation Fields"}

\subsection{Measurement in pulsed neutron fields}

In recent years, the emerging technology of particle acceleration with ultra-intense laser pulses (Macchi et al. 2013) and the commissioning of free electron lasers facilities (Paul 2010) faced the radiation dosimetry community with a new technological challenge. The time structure of the accelerated beam is characterized by ultrashort radiation bursts, in the range of hundreds of fs, and repetition rates in the range of few Hz. The stray radiation caused by the beam interaction with structural parts of the equipment or with a beam dump, maintains a very similar time structure. The result is that most of the instrumentation commonly used for continuous radiation fields, and in particular detectors operating in pulse mode, fail because the particle interaction is concentrated in a time shorter than the resolving time of the shaped detector pulse. Severe dead time losses preclude the use of such counters. For this reason, the demand of instrumentation capable of coping with pulsed and mixed radiation fields is particularly pressing. EURADOS WG11 initiated the study of instrument response focusing first on pulsed neutron fields (Caresana et al. 2014). To some extent, pulsed neutron fields are less difficult to detect than pulsed photon fields because most of neutron area detectors are based on neutron moderation. As a consequence, the original time structure of the radiation field is spread out by the thermalization time and the drift time of thermal neutrons to the sensor. Nevertheless, as some detectors are affected by severe dead time losses, it is important for radiation protection practitioners to understand the limits of usability of a specific detector in a specific radiation field.

A set of 29 instruments, including both commercial detectors and prototypes, were tested at the Helmholtz-Zentrum Berlin für Materialien und Energie (HZB). Among the instruments were 15 personal dosimeters and 14 area dosimeters. The HZB operates a proton accelerator used for eye cancer treatment, but the beam could also be delivered to an experimental room where the instrument inter-comparison described here took place. The pulsed structure of the radiation field was obtained through a kick magnet capable of directing the proton beam onto 
a tungsten target for a well-defined time, ranging from $50 \mathrm{~ns}$ to $1 \mathrm{~ms}$. The proton current was adjustable in the range of $0.5 \mathrm{pA}-300 \mathrm{nA}$. Varying the proton current and the time duration of the beam on the target allowed production of various neutron bursts with intensities spanning over five orders of magnitude in intensity. In particular, 15 different machine settings were chosen, producing reference neutron burst yields from $0.077 \mathrm{nSv}$ per burst to $470 \mathrm{nSv}$ per burst. The instrument response was ranked in terms of "half response burst dose" that is the reference dose per burst, expressed in $\mathrm{nSv}$, that causes an underestimation by a factor two in instrument reading. Table 1 shows the ranking of the tested area monitors:

Table 1 Ranking of the instruments based on the half response burst dose.

\begin{tabular}{ll}
\hline Instrument & $\begin{array}{l}\text { Half response burst dose } D_{\text {half }} \\
{[\mathrm{nSv}]}\end{array}$ \\
\hline REM -2 & $>3000$ \\
AGREM & $>3000$ \\
LUPIN BF & 1808 \\
LUPIN ${ }^{3} \mathrm{He}$ & 182 \\
LB 6419 & 28 \\
WENDI II & 42 \\
BIOREM & 79 \\
LB 6411 & 38 \\
Studsvik & 27 \\
$\quad$ 2202D & \\
RadEye & 25 \\
Harwell N91 & 19 \\
Linus & 6 \\
Cramal31 & 8 \\
LIULIN & 53 \\
\hline
\end{tabular}

The first two instruments, REM-2 (Zielczyński et al. 1996) and AGREM (Luszik-Bhadra et al. 2010) are not based on signal counting, because the former is an ion chamber and the latter is based on silver activation. The sensitivity of these detectors is considerably lower than the typical sensitivity of a rem-counter. Therefore, for the activation-based AGREM detector the delay time due to the silver delay time does not permit application where a prompt response is needed. Among the rem-counters using a proportional counter $\left({ }^{3} \mathrm{He}\right.$ or 
$\left.\mathrm{BF}_{3}\right)$ the LUPIN BF 3 (Caresana et al. 2013, 1014; Cassell et al. 2015) exhibited a superior behavior, due to the innovative front-end electronics that bypasses the amplification and shaping of the signal. As far as personal dosemeters are concerned, pulsed neutron fields do not seem to be a problem for burst dose rates up to $50 \mathrm{~Sv} / \mathrm{h}$. A possible explanation is the reduced sensitivity that shifts the problem of dead time losses to higher dose rates.

The major outcome of the inter-comparison was a clear characterization of the response of various instruments in pulsed neutron fields. This result permitted to recommend radiation protection officers a proper instrument which is suited for neutron personal/environmental monitoring in stray radiation fields around facilities providing pulsed radiation. In addition, the experiment was a unique opportunity for characterizing prototypes especially designed for coping with pulsed neutron fields. From this point of view the inter-comparison fostered the technology transfer pushing private companies to take over the production of the best performing prototypes. As example, the LB 6419/20 monitor was designed at DESY for detection and dose evaluation of radiation bursts in pulsed photon and neutron fields. At present these devices are used for control and monitoring of the FLASH accelerator among others at DESY and the European XFEL. The German company Berthold Technologies sells the LB $6419 / 20$ on the market. Another important example is the LUPIN BF 3 developed at the Polytechnic of Milan and currently marketed by the Italian company ElseNuclear srl under the commercial name of LUPIN 5401. Because of the superior behavior of this instrument, it was chosen as a reference instrument for control and monitoring around the SwissFel accelerator at PSI (Strabel et al. 2017).

\subsection{Instrument Comparison in high-energy neutron fields}

One of the prominent challenges to perform radiation protection around accelerators is the availability of reference neutron fields for instrument calibration. For neutron energies below about $20 \mathrm{MeV}$ several calibration facilities are available at PTB in Germany, IRSN in France, or NPL in United Kingdom. For higher energies, only few facilities around the world offer calibrations with quasi-mono-energetic fields (Pomp et al. 2013; Alves et al. 2015), with the added practical complexity that the availability of beam time is very limited in time (Harano et al. 2010; Mosconi et al. 2010). Besides, the instrument calibration relies also on workplace fields. In particular the CERF facility (Mitaroff et al., 2002) represents a work-place facility, although not metrologically traceable, which is widely used for instrument calibration. At 
CERF, secondary high-energy neutrons are produced by the interaction of high-energy particles (several $\mathrm{GeV}$ ) with matter. This is also the case for cosmic radiation impinging on the Earth's atmosphere or around the shielding of high-energy particle accelerators. The typical neutron spectrum, after traversing a large amount of matter, shows two energy regions mainly contributing to the total ambient dose equivalent: around $1 \mathrm{MeV}$ (evaporation peak) and around $100 \mathrm{MeV}$ (intra-nuclear cascade peak). At higher neutron energies, the neutron facility at iThemba LABS, Cape Town, South Africa, together with the German neutron metrology laboratory (PTB) provided the possibility to characterize instruments at neutron energies around $100 \mathrm{MeV}$. This was the aim of the EURADOS campaign in 2011.

This campaign is described in detail in Buffler et al. 2016. The metrological traceability was guaranteed by PTB that characterized the neutron beams in terms of energy distribution, dosimetry and geometrical dimension. Irradiations were performed at two energies, $66 \mathrm{MeV}$ and $100 \mathrm{MeV}$ and two irradiation geometries, $0^{\circ}$ and $16^{\circ}$ with respect to the direction of the proton beam impinging on a $6 \mathrm{~mm}$ thick natural $\mathrm{Li}$ target. In the $0^{\circ}$ direction, the main neutron peak $(66 \mathrm{MeV}$ or $100 \mathrm{MeV})$ contributes about half to the total fluence. The remaining part is a continuum from thermal energy to the peak energy. The irradiation at $16^{\circ}$ was characterized by the same continuum as before, but the fluence under the main peak was only a small fraction of the total fluence (Fig. 13). Subtraction of the instrument response in the two geometrical configurations can provide the instrument response to a monochromatic neutron energy.

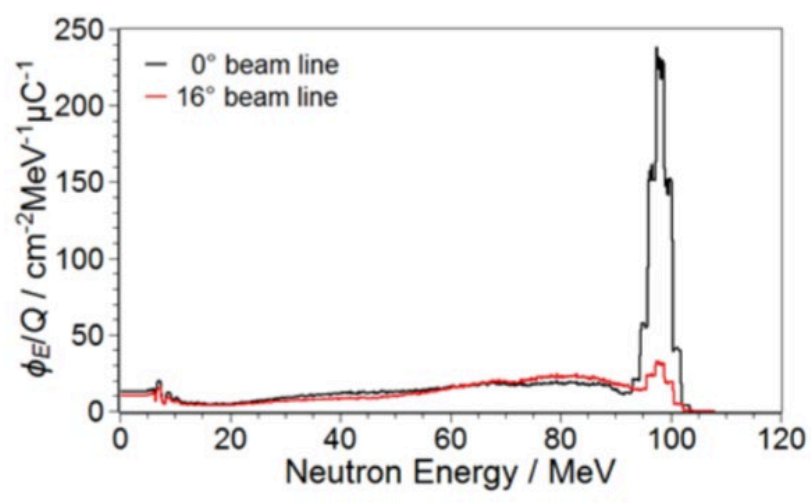

Fig. 13. Neutron spectrum in the two different geometrical configurations at iThemba LABS (Buffler et al. 2016)

Eight institutions took part in the campaign, using 13 different detectors, both active and passive. 
The campaign offered the scientific community a unique opportunity to measure the sensitivity of different kinds of instrument to monochromatic and quasi-monochromatic high energy neutrons. Because of the heterogeneity of the tested instruments (scintillators, silicon detectors, Bonner Sphere Spectrometers (BSS), PADC, Tissue-equivalent Proportional Counters (TEPC)) a direct comparison of the instrument response was not possible. However, as several institutions provided PADC personal dosimeters, a detailed comparison of the detectors response could be performed (Trompier et al. 2014) providing a better understanding of the data analysis procedures and a harmonization among personal neutron dosimetry services.

\section{WG12 "Dosimetry in Medical Imaging"}

\subsection{Eye dosimetry for operators in interventional procedures}

Interventional radiology and cardiology procedures are known to increase the radiation exposure to patient and operators requiring optimized radiation protections strategies [Carinou et al. 2014]. That became particularly urgent after the revision of the recommended annual limit for the eye lens exposure that decreased from $150 \mathrm{mSv}$ per year to $20 \mathrm{mSv}$ per year [ICRP 2012]. Monte Carlo simulations were used to reproduce the irradiation scenario and evaluate the efficacy of the possible protective interventions [Koukorava et al 2014, Ciraj Bjelac et al. 2016].

Anthropomorphic analytical models, already employed in the ORAMED project (Vanhavere et al 2011) have been modified with the aim of characterize the scattered radiation field reaching the operator head during interventional procedures. The effectiveness of the radiation protection offered by ceiling-suspended shields and lead glasses in the most common situations has been checked. For this, five beam projections (AP, PA, LLAT/LAO $90^{\circ}$, RAO $30^{\circ}, \mathrm{CRANIAL} 40^{\circ}$ ) have been considered. A sensitivity analysis has been performed checking the influence of several parameters: the operator's position with respect the patient's body; the direction of operator's head with respect to the X-ray beam axis (turning it towards or away from the beam); the use of the three different shape of protective lead glasses; the use of ceiling-suspended shielding and table shielding; the field dimensions of the primary beam on the image intensifier. 
It turned out that protective glasses with a shape guaranteeing a shielding both from lateral and from bottom-up scattered radiation can reduce the exposure of the most exposed eyes by up to a factor 10. It was also demonstrated that if positioning of ceiling-suspended shielding was not optimized, the effectiveness of protection was reduced to one tenth. It was seen that moving from femoral to radial access usually increases the scattered radiation toward the operator head (a factor of 1.5 for AP projection); but for the RAO projections, a reduction by factors 2-3 times was obtained due to the additional protection provided by the image device. To summarize, a detailed description of the spatial distribution of the scattered photons surrounding the operator's head was obtained showing that there is a preferential direction of the impinging scattered radiation, which should be carefully considered when shielding is evaluated or when an eye lens dosemeter is employed for personnel monitoring. In the future, simulations are expected to play an increasing role in radiation protection and dosimetry (Ferrari et al. 2016).

\subsection{Effects of aprons in interventional radiology and cardiology}

Staff using fluoroscopy imaging stands near the X-ray source during the medical procedures. They use shielding garments such as lead aprons, lead collars and protection glasses together with mobile ceiling-suspended screens and other protection means. The staff is thus exposed to an inhomogeneous radiation field that makes the correct assessment of the radiation exposure especially challenging. The International Commission on Radiological Protection (ICRP) provides recommendations on double dosimetry [ICRP 2001] and on the use of effective dose in interventional procedures from dosimeter readings when an apron is worn [ICRP 2018]. However, the influence of the lead apron on the response of the dosemeters worn above the apron is in general not considered. The interest in double-dosimetry has recently increased, due to the reduction of the annual eye lens dose limit for exposed workers to $20 \mathrm{mSv}$ [ICRP 2012, EC 2014]. Consequently, WG12 initiated a study with the goal to analyze the changes in the response of both, passive and active, personal dosemeters when they are placed above a lead or lead-equivalent garment (Ginjaume et al. 2019). For this, six types of passive dosemeters together with eight types of active personal dosemeters (APD) were irradiated with reference radiation beams [IEC 2005; ISO 1999] on an ISO slab phantom with and without the presence of a $0.5 \mathrm{~mm}$ lead layer. Because lead is currently being replaced by either composite lead or lead-free materials, in clinical protective garments, 
two APDs were also studied using the ISO phantom and two types of commercial aprons $(0.5$ $\mathrm{mm} \mathrm{Pb}$ equivalent). The influence of the lead apron in the response of the dosemeters was analyzed by calculating the ratio of the dosemeter reading when situated above a $0.5-\mathrm{mm}$ lead layer $\left(H_{\mathrm{p}}(10)_{\mathrm{Pb}}\right)$ and directly on the phantom surface $\left(H_{\mathrm{p}}(10)_{\mathrm{phan}}\right)$. For the lead composite apron, measurements showed no significant differences as compared to the $0.5 \mathrm{~mm} \mathrm{~Pb}$ layer. However, for the lead-free garment, there was a $10 \%$ difference for the two dosemeters and for all tested radiation beams. Furthermore it was shown that the influence of the lead layer was small for ${ }^{137} \mathrm{Cs}$ (on average $4 \%$ ), whereas for the X-ray beams all dosimeters underestimated the dose by 1\%-38\%. More specifically, for typical diagnostic X-ray energies, passive dosemeters underestimated equivalent dose by $20 \%-40 \%$ (on average: $25 \%$ ), while active dosemeters underestimated equivalent dose on average by only $6 \%$. It was concluded that when a dosemeter is worn above a protective apron, it is no longer measuring personal dose equivalent $\left(H_{\mathrm{p}}(10)\right)$ for which the dosemeter was type-tested, because part of the radiation backscattered by the body will no longer reach the dosemeter, and the backscattered spectra changes (e.g., lead aprons give rise to characteristic X-rays of 72 and $75 \mathrm{keV}$ ). It is noted, however, that the results obtained have only a small effect on the assessment of effective dose (below $5 \%$ ), because in this case the contribution from the unprotected dosemeter is small. However, when the dosemeter worn above a lead apron or a thyroid collar is directly used to estimate the equivalent dose to the eye, then the resulting underresponse can be of major importance. Since APDs do not present this limitation, their use is encouraged, not only to increase awareness of the radiation dose in real-time and to support optimization of radiation protection but also to prevent exceeding the dose limit.

\subsection{Alert levels for maximum skin dose in fluoroscopically guided procedures}

Fuoroscopically-guided interventional procedures in radiology (IR) and cardiology (IC) are techniques that have been widely used in the last decades, but may result in high doses to both patients and staff, in particular, with potentially high radiation doses to the skin of a patient (Balter et al. 2010). Consequently, WG 12 initiated a study on skin dose estimation during interventional medical procedures. In this study, patient skin dose measurements, measurements of the dose area product (DAP) and air kerma at the interventional reference point $(K a, r)$ were performed at different European hospitals for three high-dose interventional procedures. The inter-center variability of online dose indicators and their correlation with 
the maximum skin dose (MSD) were examined, with the main objectives to investigate the feasibility of generic alert levels, to compare those to published data and to assess the overall uncertainty involved in setting up the alert levels.

More specifically, patient skin dose measurements were performed for chemoembolization of the liver (TACE), neuro-embolization (NE), and percutaneous coronary intervention (PCI). For each individual procedure, fluoroscopy time, DAP or Ka,r were recorded. MSD was determined by two different dosimeters: XR-RV3 GafChromic ${ }^{\circledR}$ films or by using TL pellets and foils as described in detail by Farah et al. (2015a, 2015b) and Dabin et al. (2015). The skin dose alert level was defined as the value of the dose indicator above which it is likely that the MSD exceeds 2 Gy (alert level \#1) or 5 Gy (alert level \#2). When the data suggested a reasonable correlation a line was fitted as: DAP (or Ka,r) $=\mathrm{a}+\mathrm{b}^{*} \mathrm{MSD}$, where $\mathrm{a}$ and $\mathrm{b}$ were fit parameters. The results revealed that both DAP and Ka,r can be used to determine skin dose alert levels. The linear correlation between fluoroscopy time and MSD was much weaker. The differences in the irradiation patterns explained why the correlation between DAP and MSD was better for TACE than for NE or PCI. Furthermore, the X-ray field dimensions in TACE procedures are typically larger than those in PCI or NE procedures leading to a high DAP/MSD value (Table1) and, accordingly, higher alert level (Jarvinen et al. 2018).

The results of this study indicated that generic, hospital-independent alert levels are feasible in some interventional procedures (like chemoembolization of the liver) but should be used cautiously, only as a first approximation; hospital-specific alert levels are preferred as the final approach and should be set to reflect the clinic's specific working procedures.

\subsection{European diagnostic reference levels for interventional cardiology}

Interventional cardiac procedures may be associated with high patient doses and require special attention to protect the patients from radiation injuries such as skin erythema, cardiovascular tissue reactions or radiation-induced cancer [ICRP 120]. With technological advances, new techniques and procedures have been recently introduced such as transcatheter aortic valve implantation (TAVI) and treatment of chronic total occlusions (CTO). These procedures can potentially lead to higher patient doses and therefore require special attention to protect the patient from radiation injuries. The tool which promotes optimization in 
interventional procedures is the diagnostic reference level (DRL), which is also emphasized in the new European Basic Safety Standard [Council Directive]. DRLs should be set and regularly updated at a national or even at local (hospital) level. In the interventional cardiology the DRLs exist mostly for CA and PCI procedures and a separate survey is needed for other procedures. This motivated WG12 to work on new European DRLs for selected or recently introduced IC procedures. The work was carried out in 12 countries, 37 clinics, 50 interventional rooms and for the following different cardiac procedures: coronary angiography (CA), percutaneous coronary intervention (PCI), pacemaker implantation (PI), electrophysiological procedures (EF) and transcatheter aortic valve implantations (TAVI). The chronic total occlusions (CTO) were considered separately for PCI, when the separation was reported by the hospital. Pacemaker implantations were divided into single (SCH) and dual chamber $(\mathrm{DCH})$ procedures and implantations of cardiac resynchronization therapy (CRT) pacemaker. Total number of procedures collected was 14,922. The DRLs were determined as a $75 \%$ level (third quartile) of the distribution of the quantity under review (e.g. air kerma-area product $\mathrm{P}_{\mathrm{KA}}$ or cumulative air kerma $\mathrm{C}_{\mathrm{K}}$ ). The proposed EU values were calculated from the median of the quantity under review for each country, and from these median values the third quartile DRL was then calculated. As a result the following European DRL values for the air kerma-area product were suggested: $35 \mathrm{Gycm}^{2}$ for CA, $85 \mathrm{Gycm}^{2}$ for PCI, $130 \mathrm{Gycm}^{2}$ for TAVI, $12 \mathrm{Gycm}^{2}$ for $\mathrm{EF}, 2.5 \mathrm{Gycm}^{2}$ for $\mathrm{SCH}$ and $3.5 \mathrm{Gycm}^{2}$ for $\mathrm{DCH}$. The CA procedures that are followed by an ad hoc PCI procedure caused higher exposure compared to elective PCI procedures. Larger variations in the data were shown for the newer TAVI and EF procedures and higher values were expected at the beginning of operation as step-learning curve. [Simrad et al. 2016]. It is emphasized that the data for each country were obtained from only a few clinics which means that the median values obtained may not be representative for the country. Thus, separate national surveys should be done to establish national DRLs. It is concluded that this study provided new European DRL values proposed for CTO, TAVI and PI procedures. The results of this study can be used further to promote optimization in patient radiation protection before national or local DRLs are set and also to provide a basis for comparison when these levels are being set (Siiskonen et al. 2018).

\section{Conclusions}


As of 2019, EURADOS includes almost 600 individual scientists who are interested in the dosimetry of ionizing radiation and who are cooperating within the eight active WGs. The work of these working groups includes research projects, education and training actions, and organization of intercomparisons. The results obtained by various activities of EURADOS and its WGs are summarized in dedicated EURADOS Reports. Since 2012, 19 EURADOS Reports have been published which are all free for download from the EURADOS website (www.eurados.org). Moreover, EURADOS WGs publish regularly in peer-reviewed international journals, and a selection of these papers is referenced in the reference list of this paper. More specifically, since the last decade (2009 - 2018), more than 100 publications appeared in the open scientific literature demonstrating the continuous efforts of EURADOS and its members to contribute towards scientific advances in the field of radiation dose assessment.

Finally it is important to note that EURADOS is a self-sustainable scientific network with financial resources from membership fees, income of intercomparison exercises and trainings and other actions, and levies from third party funding of research projects. Because of its independent nature, EURADOS will continue its activities in the future and, by this, will contribute towards a continuous improvement of the dosimetry of ionizing radiation in Europe and beyond.

\section{Acknowledgements}

The authors thank the following individuals for their contributions: Barbara Caccia, Carmen Villagrasa, Giorgio Baiocco, Jonathan Eakins, Olivera Ciraj Bjelac, Paolo Ferrari, Merce Ginjaume 


\section{References}

\section{Intro}

Rühm, W., Schuhmacher, H., 2017. EURADOS - A success story for European Cooperation in the dosimetry of ionizing radiation. StrahlenschutzPRAXIS 3, 36-38.

Rühm, W., Bottollier-Depois, J.F., Gilvin, P., Harrison, R., Knežević, Ž., Lopez, M. A., Tanner, R., Vargas, A., Woda, C., 2018. The work programme of EURADOS on internal and external dosimetry, Annals of ICRP, 47(3-4), 20-34.

SRA

Rühm, W., Fantuzzi, E., Harrison, R., Schuhmacher, H., Vanhavere, F., Alves, J.,Bottollier Depois, J.F., Fattibene, P., Knezevic, Z., Lopez, M.A., Mayer, S., Miljanic, S., Neumaier, S., Olko, P., Stadtmann, H., Tanner, R. Woda, C., 2014. Vision for Radiation Dosimetry over the next two decades - Strategic Research Agenda of the European Radiaiton Dosimetry Group. EURADOS Report 2014-01, Braunschweig, Germany.

Rühm, W., Fantuzzi, E., Harrison, R., Schuhmacher, H., Vanhavere, F., Alves, J., Bottollier Depois, J.F., Fattibene, P., Knezevic, Z., Lopez, M.A., Mayer, S., Miljanic, S., Neumaier, S., Olko, P., Stadtmann, H., Tanner, R. Woda, C., 2016. EURADOS Strategic Research Agenda: Vision for Dosimetry of Ionising Radiation. Radiat. Prot. Dosim. 168, 223-234.

Rühm, W., Friedl, A.A., Wojcik, A., 2017a. Coordinated radiation protection research in Europe: Is it the beginning of a new era? Radiat. Environ. Biophys. 57, 1-4.

Rühm, W., Knežević, Ž., Fantuzzi, E., Harrison, R., Schuhmacher, H., Vanhavere, F., Alves, J., Bottollier Depois, J.F., Fattibene, P., Gilvin, P., Lopez, M.A., Mayer, S., Miljanić, S., Olko, P., Stadtmann, H., Tanner, R., Vargas, A., Woda, C., 2017b. EURADOS Stakeholder Workshop on June 30th, 2016. EURADOS Report 2017-02, Braunschweig, Germany.

WG2

Alves, J.G., Fantuzzi, E., Rühm, W., Gilvin, P., Vargas, A., Tanner, R., Rabus, H., Lopez, M.A., Breustedt, B., Harrison, R., Stolarczyk, L., Fattibene, P., Woda, C., Caresana, M., Knežević, Ž., Bottollier-Depois, J.F., Clairand, I., Mayer, S., Miljanic, S., Olko, P., Schuhmacher, H., Stadtmann, H., Vanhavere, F., 2019. EURADOS Education and Training activities in the 2009-2019 period. J. Radiol. Prot., in press, doi: 10.1088/1361-6498/ab3256.

Chevallier, M.-A., Fantuzzi, E., Cruz-Suarez, R., Luszik-Bhadra, M., Mayer, S., Thomas, D. J., Tanner, R., Vanhavere, F., 2016. EURADOS IC2012n: Further Information Derived from a EURADOS International Comparison of Neutron Personal Dosemeters. Radiat. Prot. Dosim. 170, 78-81.

European Commission, 2009. Radiation Protection No 160 - Technical Recommendations ofr Monitoring Individuals Occupationally Exposed to External Radiation. Directorate-General for Energy and Transport, Directorate H - Nuclear Energy, Unit H.4 - Radiation Protection.

Fantuzzi, E, Chevallier, M-A, Cruz-Suarez, R, Luszik-Bhadra, M, Mayer, S, Thomas, D J, Tanner, R.J, Vanhavere, F., 2014. EURADOS Intercomparison 2012 for Neutron Dosemeters. http://www.eurados.org, EURADOS Report 2014-02.

Figel, M., Stadtmann, H., Grimbergen, T. W. M., McWhan, A., Romero, A. M., 2016. EURADOS Intercomparisons on whole-body dosemeters for photons from 2008 to 2014. Radiat. Prot. Dosim. 170, 113-116.

Figel, M., Stadtmann, H., Grimbergen, T.W.M., McWhan, A., Romero, A.M., 2019. EURADOS report in preparation. EURADOS Intercomparison 2016 for Whole Body Dosemeters in Photon Fields.

Gilvin, P., Alves, J.G., Cherestes, C., van Dijk, J.W.E, Lehtinen, M., Rossi, F., Vekic, B., 2014. Quality assurance in individual monitoring: A summary of the EURADOS survey 2012. Rad. Meas. 71, 434-437 doi: 10.1016/j.radmeas.2014.07.003.

Grimbergen, T., Figel, M., McWhan, A., Romero, A. M., Stadtmann, H., 2016. EURADOS programme of intercomparisons for individual monitoring services: Seven years of development and future plans. Radiat. Prot. Dosim. 170, 90-94.

Romero, A. M., Grimbergen, T., McWhan, A., Stadtmann, H., Fantuzzi, E., Clairand, I., Neumaier, S., Figel, M., Dombrowski, H., 2016. EURADOS Intercomparisons in external radiation dosimetry: Similarities and differences among exercises for whole-body photon, whole-body neutron, extremity, eye-lens and passive area dosemeters. Radiat. Prot. Dosim. 170, 82-85.

Stadtmann, H., McWhan, A.F., Grimbergen, T.W.M, Figel, M., Romero, A.M., Gärtner, C., Hranitzky, C., 2018. EURADOS Intercomparison 2014 for Whole Body Dosemeters in Photon Fields. http://www.eurados.org. EURADOS Report 2018-01. 
Stadtmann, H., Grimbergen, T. W. M., Figel, M., Romero, A. M., McWhan, A. F., Gärtner, C., 2016. The Results of the EURADOS Intercomparison IC2014 for Whole-Body Dosemeters in Photon Fields. Radiat. Prot. Dosim. 170, 90-94.

Stadtmann, H., McWhan, A., Figel, M., Grimbergen, T W M., Romero, A. M., Gärtner, C., 2017. EURADOS Intercomparisons for individual monitoring services: Results of the 2015 extremity dosemeter intercomparison for photon and beta radiations. Radiat. Meas. 106, 285-289.

WG3

Camp, A., Vargas, A., 2014. Ambient Dose estimation $\mathrm{H}^{*}(10)$ form $\mathrm{LaBr}_{3}(\mathrm{Ce})$ spectra. Radiat. Prot. Dosim. $160,264-268$.

Dombrowski, H., Duch, M.A., Hranitzky, C., Kleinau, P., Neumaier, S., Ranogajec-Komor, M., Rodriguez, R., 2017. EURADOS intercomaparisson of Passive $H^{*}(10)$ area dosemeteres 2014. Radiat. Meas. 106, 229-234.

Duch, M.A., Dombrowski, H., Hranitzky, C. Kleinau, P., Neumaier, S., Ranogajec-Komor, M., Rodriguez, R., 2017. Status of passive environmental dosimetry in Europe. Radiat. Meas. 106, 242-245.

Royo, P., Pastor, E.,Macias, M., Cuadrado, R., Barrado, C. and Vargas, A., 2018. An Unmanned Aircraft System to Detect a Radiological Point Source Using RIMA Software Architecture. Remote Sens. 1712.

Vargas, A., Cornejo, N., Camp, A., 2018. Comparisson of methods for $H^{*}(10)$ calculations form measured WG6 $\mathrm{LaBr} 3(\mathrm{Ce})$ detector spectra. Applied Radiation and Isotopes 137, 241-249.

Caccia, B., Le Roy, M., Blideanu, V., Andenna, C., Arun, C., Czarneck, D., El Bardouni, T., Gschwind, R., Huot, H., Martin, E., Zink, K., Zoubair, M., Price, R., de Carlan, L., 2017. EURADOS intercomparison exercise on Monte Carlo modelling of a medical linear accelerator, Annali dell'Istituto Superiore di Sanità 53, 314-321.

Discher, M., Eakins J. S., Woda, C. and Tanner, R, 2019. Translation of the absorbed dose in the mobile phone to organ doses of an ICRP voxel phantom using MCNPX simulation of an Ir-192 point source. Radiat. Meas. [In Preparation].

Eakins, J. S., Ainsbury, E. A., 2018a. Quantities for assessing high doses to the body: a short review of the current status. J. Radiol. Prot. 38, 731-742.

Eakins, J. S., Ainsbury, E. A., 2018b. Quantities for assessing high doses to the body: a calculational approach. J. Radiol. Prot. 38, 743-762.

Friedland, W., Dingfelder, M., Kundrat, P., Jacob, P., 2011. DNA targets and radiation effects in the biophysical Monte Carlo simulation code PARTRAC. Mutat. Res. 711, 28-40.

Gervais, B., Beuve, M., Olivera, G.H., Galassi, M.E., 2006. Numerical simulation of multiple ionization and high LET effects in liquid water radiolysis. Radiat. Phys. Chem. 75, 493-513.

Gómez-Ros, J. M., Bedogni, R., Domingo, C., Eakins, J. S., Roberts, N., Tanner, R. J., 2018. International comparison exercise on neutron spectra unfolding in bonner spheres spectrometry: problem description and preliminary analysis, Radiat. Prot. Dosim. 180 (1-4), 70-74.

Howell, R. W., 1992. Radiation spectra for Auger electron emitting radionuclides: Report No. 2 of AAPM Nuclear Medicine Task Group No. 6. Med. Phys. 19(6), 1371-1383.

ICRP, 2007. The 2007 recommendations of the international commission on radiological protection ICRP Publication 103 Ann. ICRP 37.

Incerti, S., Ivanchenko, A., Karamitros, M., Mantero, A., Moretto, P., Tran, H.N., Mascialino, B., Champion, C., Ivanchenko, V.N., Bernal, M.A., Francis, Z., Villagrasa, C., Baldacchin, G., Guèye, P., Capra, R., Nieminen, P., Zacharatou, C., 2010. Comparison of GEANT4 very low energy cross section models with experimental data in water. Med. Phys. 37, 4692-4708.

Pelowitz, D. B., 2011. MCNPX User's manual, Version 2.7.0. LANL Report: LA-CP-11-00438.

Trompier, F., Burbidge, C., Bassinet, C., Baumann, M., Bortolin, E., De Angelis, C., Eakins, J., Della Monaca, S., Fattibene, P., Quattrini, M.C., Tanner, R., Wieser, A., Woda, C., 2017. Overview of physical dosimetry methods for triage application integrated in the new European network RENEB. Int. J. Radiat. Biol. 12:1-10.

Villagrasa, C., Bordage, M.-C., Bueno, M., Bug, M., Chiriotti, S., Gargioni, E., Heide, B., Nettelbeck, H., Parisi, A., Rabus, H., 2018. Assessing the contribution of cross-sections to the uncertainty of Monte Carlo calculations in micro- and nanodosimetry. Radiat. Prot. Dosim. 183 (1-2), 11-16.

WG7

Breustedt, B., Blanchardon, E., Berard, P., Fritsch, P., Giussani, A., Lopez, M.A., Luciani, A., Nosske, D., Piechowski, J., Schimmelpfeng, J., Sérandour, A.-L., 2009. Biokinetic modelling of DTPA decorporation therapy: the CONRAD approach, Radiat. Prot. Dosim. 134, 38-48.

Breustedt, B., Avtandilashvili, M., McComish, S. L., Tolmachev, S. Y.. 2019. USTUR Case 0846: Modeling Americium Biokinetics After Intensive Decorporation Therapy. Health Phys. 117, 168-178. 
Breustedt, B., Broggio, D., Gomez-Ros, J. M., Leone, D., Marzocchi, O., Poelz, S., Shutt, A., Lopez, M. A., 2016. The EURADOS-KIT training course on Monte Carlo methods for the calibration of body counters. Radiat. Prot. Dosim. 170, 446-450.

Broggio, D., Bento, J., Cardenas-Mendez, E., Farah, J., Fonseca, T., Freire, L., Konvalinka, C., Liu, :, Caldeira, M., Capello, K., Cowan, P., Cruzate, J.-A., Gómez-Ros, J.-M., Gossio, S., Heide, B., Huikari, J., Hunt, J., Kinase, S., Kramer, G.H., Kurihara, O., Kyrielis, A., Lebacq, A.-L., Leone, D., Li, J., Li, C., Milhailescu, L.-C., Moraleda, M., Oliveira, C., Puerta, N., Reichelt, U., Simões, C., Sommer, D., Takahashi, M., Teles, P., Vanhavere, F., Vrba, T., Franck, D., Gualdrini, G., Lopez, M.A., 2012. Monte Carlo modelling for the in vivo lung monitoring of enriched uranium: Results of an international comparison. Radiat. Meas. 47, 467- 566.

Castellani C.-M., Marsh J. W., Hurtgen C., Blanchardon E., Berard P., Giussani A., Lopez M.A., 2013. IDEAS guidelines (Version 2) for the estimation of committed doses from Incorporation monitoring data, EURADOS Report 2013-01, Braunschweig, March 2013, ISSN 2226-8057.

Li, C., Battisti, P., Berard, P., Cazoulat, A., Cuellar, A., Cruz-Suarez, R:, Dai, X., Giardina, I., Hammond, D., Hernandez, C., Kiser, S., Ko, R., Kramer-Tremblay, S:, Lecompte, Y., Navarro, E., Navas, C., Sadi, B:, Sierra, I., Verrezen, F:, Lopez, M.A., 2014. EURADOS Intercomparison on Emergency Bioassay. Radiat. Prot. Dosim. 167(4), 472-484.

Davesne, E., Laurent, O., Lopez, M. A., 2018. How to assess internal doses for epidemiological studies and for emergency response? An overview of differences with routine operational radiation protection approach, Radiat. Meas. 115, 20-28.

Davesne, E., Bull, R., Anderson, J., Bingham, D., Birchall, A., Castellani, C.M., Challeton-de Vathaire, C., Fernandez, M.L., Froning, M., Giomi, A., Lebacq, A.L., Ośko, J., Gomez Parada, I., Pántya, A., Rojas, A.G., Rojo, A., Takahashi, M., Tani, K., Blanchardon, E., 2017. Uncertainties in internal dose assessment: Lifetime dose assessment for three example workers occupationally exposed to uranium Analysing the intercomparison results, EURADOS Report 2017-03, Neuherberg, October 2017, ISSN 2226-8057.

European Commission, 2018, Technical Recommendations for Monitoring Individuals for Occupational Intakes of Radionuclides, Radiation Protection Series, Report No. 188, Luxembourg.

Giussani, A., Lopez, M.A., Testa, A., 2019. The EURADOS work towards a review on retrospective dosimetry after incorporation of radionuclides, Radiat. Prot. Dosim., https://doi.org/10.1093/rpd/ncy244.

Hickman, D. P., Collins, L., Didier, F., Harding N. R., Jeffers,L. K., López Ponte M. A., I. Tai. I. L., 2018. Thyroid phantom measurements in joint EURADOS-LLNL intercomparison exercise. Radiat. Prot. Dosim. 178(2), 152-159.

Leggett, R. W., Williams, L. R., Melo, D. R. and Lipsztein, J. L. 2003. A physiologically based biokinetic model for cesium in the human body. Sci. Total Environ. 317, 235-255.

Li, W.B., Klein, W., Blanchardon, E., Puncher, M., Leggett, R.W., Oeh, U., Breustedt, B., Nosske, D., Lopez, M. A., 2015. Parameter uncertainty analysis of a biokinetic model of caesium. Radiat. Prot. Dosim. 163, $37-57$.

Lopez, M.A., Broggio, D., Capello, K., Cardenas-Mendez,E., El-Faramawy, Franck, D., James, A.C., Kramer, G.H., Lynch, T.P., Navarro, J.F., Navarro, T., Perez, B., Rühm, W., Tolmachev, S.Y., Weitzenegger, E., 2011. EURADOS Intercomparison on measurements and Monte Carlo modeling for the assessment of Americium in a USTUR leg phantom. Radiat. Prot. Dosim. 144, 295-299.

Lopez, M.A., Etherington, G., Castellani, C.M., Franck, D., Hurtgen, C., Marsh, J.W., Nosske, D., Breustedt, B., Blanchardon, E., Andrasi, A., Bailey, M.R., Balashazy, I., Battisti, P., Bérard, P., Birchall, A., Broggio, D., Challeton-de-Vathaire, C., Cruz-Suarez, R., Doerfel, H., Giussani, A., Hodgson, A., Koukouliou, V., Kramer, G.H., Le Guen, B., Luciani, A., Malatova, I., Molokanov, A., Moraleda, M., Muikku, M., Oeh, U., Puncher, M., Rahola,T., Stradling, N., Vrba, T., 2008. Internal Dosimetry: Towards Harmonization and Coordination of Research. Radiat. Prot. Dosim. 131(1), 28-33.

Lopez, M.A., Nogueira, P., Vrba, T., Tanner, R.J., Rühm, W., Tolmachev, S.Y. 2019. Measurements and Monte Carlo Simulations of 241Am Activities in Three Skull Phantoms: EURADOS-USTUR Collaboration. Heath Phys., 117, 193-201.

Nogueira, P., Rühm, W., Lopez, M.A., Vrba, T., Buchholz, W., Fojtík, P., Etherington, G., Broggio, D., Huikari, J., Marzocchi, O., Lynch, T., Lebacq, A.L., Li, C., Ośko, J., Malátova, I., Frank, D., Breustedt, B., Leone, D., Scott, J., Shutt, A., Hauck, B., Capello, K., Pérez López, B., Navarro Amaro, J.F., Pliszczyński, T., Fantínová, K., Tolmachev, S.Y., 2015. EURADOS ${ }^{241}$ Am skull measurement intercomparison. Radiat. Meas. 82:64-73.

Stather, J.W., Smith, H., Bailey, M.R., Birchall, A., Bulman, R.A., Crawley, F.E., 1983. The retention of ${ }^{14}$ CDTPA in human volunteers after inhalation or intravenous injection. Health Phys. 44: 45-52, 1983.

Vrba, T., Nogueira, P., Broggio, D., Caldeira, M., Capello, K., Fantínová, K., Figueira, C., Hunt, J., Leone, D., Murugan, M., Marzocchi, O., Moraleda, M., Shutt, A., Suh, S., Takahashi, M., Tymińska, K., Lopez, 
M.A., Tanner, R., 2014. EURADOS intercomparison exercise on MC modeling for the in-vivo monitoring of Am-241 in skull phantoms (Part I). Radiat. Phys. Chem. 104:332-338.

Vrba, T., Broggio, D., Caldeira, M., Capello, K., Fantinova, K., Franck, D., Gomez-Ros, J.M., Hunt, J., Kinase, S., Leone, D., Lombardo, P.A., Manohari, M., Marzocchi, O., Moraleda, M., Nogueira, P., Ośko, J., Arron, S., Suhl, S., Takahashi, M., Teles, P., Tremblay, M., Tymińska, K., Lopez, M.A., Tanner, R. 2015. EURADOS intercomparison exercise on MC modelling for the in-vivo monitoring of Am-241 in WG9 skull phantoms (Part II and III). Radiat. Phys. Chem. 113:59- 71.

De Saint-Hubert, M., Majer, M., Hršak, H., Heinrich, Z., Knežević, Ž., Miljanić, S., Porwoł, P., Stolarczyk, L., Vanhavere, F., Harrison,,R., 2018. Out-of-field doses in children treated for large arteriovenous malformations using hypofractionated gamma knife radiosurgery and intensity modulated radiotherapy. Radiat. Prot. Dosim. 181(2),100-110.

Knežević, Ž., Ambrozova, I., Domingo, C., De Saint-Hubert, M., Majer, M., Martinez-Rovira, I., Miljanić, S., Mojżeszek, N., Porwol, P., Ploc, O., Romero-Expósito, M., Stolarczyk, L., Trinkl, S., Harrison, R., Olko, P., 2018. Comparison of response of passive dosimetry systems in scanning proton radiotherapy - a study using paediatric anthropomorphic phantoms. Radiat. Prot. Dosim. 180(1-4), 256-260.

Stolarczyk, L., Tinkl, S., Romero-Expósito, M., Mojżeszek, N., Ambrozova, I., Domingo, C., Davidkova, M., Farah, J., Klodowska, M., Knežević, Ž., Liszka, M., Majer, M., Miljanić, S., Ploc, O., Schwarz, M., Harrison, R.M., Olko, P., 2018. Dose Distribution of Secondary Radiation in a Water Phantom for a Proton Pencil Beam — EURADOS WG9 Intercomparison Exercise. Phys. Med. Biol. 63, 085017.

Farah, J., De Saint-Hubert, M., Mojzeszek, N., Chiriotti, S., Gryzinski, M., Ploc, O., Trompier, F., Turek, K., Vanhavere, F., Olko, P., 2017. Performance tests and comparison of microdosimetric measurements with four tissue-equivalent proportional counters in scanning proton therapy. Radiat. Meas. 96, 42-52.

Majer, M., Stolarczyk, L., De Saint-Hubert, M., Kabat, D., Knežević, Ž., Miljanić, S., Mojżeszek, N., Harrison, R., 2017. Out-of-field dose measurements for 3D conformal and intensity modulated radiotherapy of a paediatric brain tumour. Radiat. Prot. Dosim. 176, 331-340.

Mojżeszek, N., Farah, J., Kłodowska, M., Ploc, O., Stolarczyk, L., Waligórski, M.P.R., Olko, P., 2017. Measurement of stray neutron doses inside the treatment room from a proton pencil beam scanning system. Physica Medica: European Journal of Medical Physics, 34, 80-84.

Schneider, C., Newhauser, W. D., Jagetic, L., Schneider, U., Kaderka, R., Miljanić, S., Knežević, Ž., Stolarczyk, L., Durante, M., Harrison, R., 2017. A descriptive andbroadly applicable model of therapeutic and stray absorbed dose from $6 \mathrm{MV}$ to $25 \mathrm{MV}$ photon beams. Med. Phys. 44, 3805-3814.

Mares, V., Romero-Expósito, M., Farah, J., Trink1, S., Domingo, C., Dommert, M., Stolarczyk, L., Van Ryckeghem, L., Wielunski, M., Olko, P., Harrison, R., 2016. A comprehensive spectrometry study of stray neutron radiation field in scanning proton therapy. Physics in Medicine and Biology 61, 41274140 .

Farah, J., Mares, V., Romero-Expósito, M., Trinkl, S., Domingo, C., Dufek, V., Klodowska, M., Kubancak, J., Knežević, Ž., Liszka, M., Majer, M., Miljanić, S., Ploc, O., Schinner, K., Stolarczyk, L., Trompier, F., Wielunski, M., Olko, P., Harrison, R.M., 2015. "Measurement of Stray Radiation within a Scanning Proton Therapy Facility: EURADOS WG9 Intercomparison Exercise of Active Dosimetry Systems." Medical physics 42(5harvard): 2572-84. http://www.ncbi.nlm.nih.gov/pubmed/25979049 (December 6,

WG10 2016).

Ainsbury, E.A., Samaga, D., Della Monaca, S., Marrale, M., Bassinet, C., Burbidge, C.I., Correcher, V., Discher, M., Eakins, J., Fattibene, P., Güçlü, I., Higueras, M., Lund, E., Maltar-Strmecki, N., McKeever, S.W.S., Rääf, C.L., Sholom, S., Veronese, I., Wieser, A., Woda, C., Trompier, F., 2018. Uncertainty on radiation doses estimated by biological and retrospective physical methods. Radiat. Prot. Dosim. 178, $382-404$.

Ainsbury, E., Badie, C., Barnard, S., Manning, G., Moquet, J., Abend, M., Bassinet, C., Bortolin, E., Bossin, L., Bricknell, C., Brzoska, K., Čemusová, Z., Christiansson, M., Cosler, G., Della Monaca, S., Desangles, F., Discher, M., Doucha-Senf, S., Eakins, J., Fattibene, P., Gregoire, E., Guogyte, K., Kriehuber, R., Lee, J., Lloyd, D., Lyng, F., Macaeva, E., Majewski, M., McKeever, S.W.S., Meade, A., M'kacher, R., Medipally, D., Oestreicher, U., Oskamp, D., Pateux, J., Port, M., Quattrini, M.C., Quintens, R., Ricoul, M., Roy, L., Sabatier, L., Sholom, S., Strunz, S., Trompier, F., Valente, M., van Hoey, O., Veronese, I., Wojcik, A., Woda, C. 2017. Integration of new biological and physical retrospective dosimetry methods into EU emergency response plans - joint RENEB and EURADOS inter-laboratory comparisons. Int. J. Radiat. Biol. 93, 99-109.

Bailiff, I.K, Sholom, S., McKeever, S.W.S., 2016. Retrospective and emergency dosimetry in response to radiological incidents and nuclear mass-casualty events: A review. Radiat. Meas. 94, 83-139. 
Helton, J. C. 2008. Uncertainty and sensitivity analysis for models of complex systems. In: Lecture Notes in Computational Science and Engineering book series (LNCSE, volume 62). (Berlin, Heidelberg: Springer Berlin Heidelberg).

Kulka U, Wojcik A. 2017. Special issue: Networking in biological and EPR/OSL dosimetry: the European RENEB platform for emergency preparedness and research. Int. J. Radiat. Biol. 93(1):1.

\section{WG11}

Macchi, A., Borghesi, M., Passoni, M., 2013. Ion acceleration by superintense laser-plasma interaction. Rev. Modern Phys. 85:751-93.

Paul, S.I., 2010. SwissFEL - Conceptual design report. Switzerland.

Caresana, M., Denker, A., Esposito, A., Ferrarini, M., Golnik, N., Hohmann, E., Leuschner, A., LuszikBhadra, Manessi, M.G., Mayer, S., Ott, K., Röhrich, J., Silari, M., Trompier, F., Volnhals, M., Wielunski, M., 2014. Intercomparison of radiation protection instrumentation in a pulsed neutron field. Nucl. Instrum. Meth. Phys. Res. Sect. A 737:203-213.

Zielczyński, M., Golnik, N., Rusinowski, Z., 1996. A computer controlled ambient dose equivalent meter based on a recombination chamber. Nucl. Inst. Meth. Phys. Res. Sect. A 370(2):563-567.

Luszik-Bhadra, M., Hohmann, E., Otto, T., 2010. A new neutron monitor with silver activation. Radiat. Meas. 45(10):1258-1262.

Caresana, M., Ferrarini, M., Manessi, GP., Silari, M., Varoli, V., 2013. LUPIN, a new instrument for pulsed neutron fields. Nucl. Instrum. Methods Phys. Res. Sect. A. 712:15-26.

Caresana, M., Cassell, C., Ferrarini, M., Hohmann, E., Manessi, G.P., Mayer, S., Silari, M., Varoli, V., 2014. A new version of the LUPIN detector: Improvements and latest experimental verification. Rev Sci Instrum. 85(6).

Cassell, C., Ferrarini, M., Rosenfeld, A., Caresana, M.. 2015. A novel technique for compensation of space charge effects in the LUPIN-II detector. Nucl. Instrum. Methods Phys. Res. Sect. A. 804:113-117.

Strabel, C., Fuchs, A., Galev, R., Hohmann, E., Lüscher, R., Musto, E., Mayer, S., 2017. The future SwissFEL facility - challenges from a radiation protection point of view. EPJ Web of Conferences 153:07026.

Pomp, S., Bartlett, D.T., Mayer, S., Reitz, G., Röttger, S., Silari, M., Smit, F.D., Vincke, H., Yasuda, H., 2013. High-energy quasi-monoenergetic neutron fields: existing facilities and future needs. EURADOS Report 2013-02, Braunschweig, Germany.

Alves, J., Bottollier-Depois, J.F., Fantuzzi, E., Fattibene, P., Lopez, M.A., Mayer, S., Miljanic, S., Olko, P., Rühm, W., Schuhmacher, H., Stadtmann, H., Vanhavere, F., 2015. Letter to the Editor. Radiat. Prot. Dosim. 163, 268.

Harano, H., Matsumoto, T., Tanimura, Y., Shikaze, Y., Baba, M., Nakamura, T., 2010. Monoenergetic and quasi-monoenergetic neutron reference fields in Japan. Radiat. Meas. 45(10):1076-1082.

Mosconi, M., Musonza, E., Buffler, A., Nolte, R., Röttger, S., Smit, F.D., 2010. Characterisation of the highenergy neutron beam at iThemba LABS. Radiat. Meas. 45(10): 1342-1345.

Mitaroff, A., Cern, M,S., 2002. The CERN-EU high-energy reference field (CERF) facility for dosimetry at commercial flight altitudes and in space. Radiat. Prot. Dosim. 102(1):7-22.

Buffler, A., Reitz, G., Röttger, S., Smit, F.D., Wissmann, F. (eds), 2016. Irradiations at the high-energy neutron facility at iThemba LABS. EURADOS Report 2016-02, Neuherberg, Germany.

Trompier, F., Boschung, M., Buffler, A., Domingo, C., Cale, E., Chevallier, M.A., Esposito, A., Ferrarini, M., Geduld, D.R., Hager, L., Hohmann, E., Mayer, S., Musso, A., Romero-Esposito, M., Röttger, S., Smit, F.D., Sashala Naik, A., Tanner, R., Wissmann, F., Caresana, M., 2014. A comparison of the response of PADC neutron dosemeters in high-energy neutron fields. Radiat. Prot. Dosim. 161(1-4):78-81.

\section{WG12}

Carinou, E., Ginjaume, M., O’Connor, U., Kopec, R., Sans Merce, M., 2014. Status of eye lens radiation dose monitoring in European hospitals J. Radiol. Prot. 34, 729-39

Ciraj Bjelac, O., Carinou, E., Ferrari, P., Gingaume, M., Sans Merce, M., O’Connor, U., 2016. Occupational exposure of the eye lens in interventional procedures: How to assess and manage radiation dose. J. Am. Coll. Radiol. 13(11):1347-1353.

ICRP, 2012. ICRP Statement on tissue reactions / early and late effects of radiation in normal tissues and organs threshold doses for tissue reactions in a radiation protection context. ICRP Publication 118, Ann. ICRP 41(1/2).

Koukorava, C., Farah, J., Struelens, L., Clairand, I., Donadille, L., Vanhavere, F., Dimitriou, P., 2014. Efficiency of radiation protection equipment in interventional radiology: a systematic Monte Carlo study of eye lens and whole body doses J. Radiol. Prot. 34, 509-528.

Vanhavere, F., Carinou, E., Domienik, J., Donadille, L., Ginjaume, M., Gualdrini, G., Koukorava, C., Krim, S., Nikodemova, D., Ruiz-Lopez, N., Sans-Merce, M., Struelens, L., 2011. Measurements of eye lens doses in interventional radiology and cardiology: Final results of the ORAMED project Radiat. Meas. 46 1243-1247. 
Ferrari, P., Becker, F., Carinou, E., Chumak, V., Farah, J., Jovanovic, Z., Krstic, D., Morgun, A., Principi, S., Teles, P., 2016. Monte Carlo study of the scattered radiation field near the eyes of the operator in interventional procedures. J. Radiol. Prot. 36(4), 902-921

Ginjaume, M., Carinou, E., Brodecki, M., Clairand, I., Domienik, J., Exner, L., Ferrari, P., Jovanović, Z., Krstic, D., Principi, S., Van Hoey, O., Vanhavere F., 2019. Effect of the radiation protective apron on the response of active and passive personal dosemeters used in interventional radiology and cardiology. J. Radiol. Prot. 39, 97-112.

EC 2014. "Council Directive 2013/59/Euratom of 5 December 2013 Laying down Basic Safety Standards for Protection against the Dangers Arising from Exposure to Ionising Radiation, and Repealing Directives 89/618/Euratom, 90/641/Euratom, 96/29/Euratom, 97/43/Euratom and 2003/122/Euratom”.

ICRP, 2001. ICRP Publication 85. "Avoidance of Radiation Injuries from Medical Interventional Procedures". Ann. ICRP 30 (2).

ICRP, 2012. ICRP Publication 118. "ICRP Statement on Tissue Reactions / Early and Late Effects of Radiation in Normal Tissues and Organs - Threshold Doses for Tissue Reactions in a Radiation Protection Context”. Ann. ICRP 41(1/2).

ICRP, 2018. Occupational radiological protection in interventional procedures. ICRP Publication 139. Ann. ICRP 47(2).

IEC. 2005. IEC 61267 Ed.2. "Medical diagnostic X-ray equipment-radiation conditions for use in the determination of characteristics". IEC, Geneva.

ISO. 1999. ISO 4037-3. "X and gamma reference radiation for calibrating dosemeters and doserate meters and for determining their response as a function of photon energy - Part 3: calibration of area and personal dosemeters and the measurement of their response as a function of energy and angle of incidence". ISO, Geneva.

Balter, S., Hopewell J.W., Miller, D.L., Wagner, L.K., Zelefsky, M.J., 2015. Fluoroscopically Guided Interventional Procedures: A Review of Radiation Effects on Patients' Skin and Hair, Radiology, 254, 326-341.

Dabin, J., Negri, A., Farah, J., Ciraj-Bjelac, O., Clairand, I., De Angelis, C., Domienik, J., Jarvinen, H., Kopec, R., Majer, M., Malchair, F., Novák, L., Siiskonen, T., Vanhavere, F., Trianni, A., Knežević, Ž., 2015. Characterization of grids of point detectors in maximum skin dose measurement in fluoroscopically-guided interventional procedures, Phys. Med. 31, 1112-17.

Farah, J., Trianni, A., Ciraj-Bjelac, O., Clairand, I., De Angelis, C., Delle Canne, S., Hadid, L., Huet, C., Jarvinen, H., Negri, A., Novák, L., Pinto, M., Siiskonen, T., Waryn, M.J., Knežević, Ž., 2015 a. Characterization of XR-RV3 GafChromicTM films in standard laboratory and clinical conditions and means to estimate uncertainties and reduce errors, Med. Phys. 42(7), 4211-26.

Farah, J., Trianni, A., Carinou, E., Ciraj-Bjelac, O, Clairand, I., Dabin, J., 2015b. Measurement of maximum skin dose interventional radiology and cardiology and challenges in the set-up of European alert thresholds, Rad. Prot. Dos. 164, 138-42.

Jarvinen, H., Farah, J., Siiskonen, T., Ciraj-Bjelac, O., Dabin, J., Carinou, E., Domienik, J., Kluszczynski, D., Knežević, Ž., Kopec, R., Majer, M., Malchair, F., Negri, A., Pankowski, P., Sarmento, S., Trianni, A., 2018. Feasibility of setting up generic alert levels for maximum skin dose in fluoroscopically guided procedures, Phys Med. 46, 67-74.

Council directive 2013/59/EURATOM of 5 December 2013. Laying down basic safety standards for protection against the dangers arising from exposure to ionizing radiation.

ICRP Publication 120. Radiological protection in cardiology. Ann ICRP 2013;42(1).

Simard, T., Hibbert, B., Natarajan, M.K., Mercuri, M., Hetherington, S.L., Wright, R., Delewi, R., Piek, J., Lehmann, R., Ruzsa, Z., Lange, H.W., Geijer, H., Sandborg, M., Kansal, V., Bernick, J., Di Santo, P., Pourdjabbar, A., Ramirez, F.D., Chow, B.J., Chong, A.Y., Labinaz, M., Le May, M.R., O'Brien, E.R., Wells, G.A., So, D., 2016. Impact of center experience on patient radiation exposure during transradial coronary angiography and percutaneous intervention: a patient-level, international, collaborative multicenter analysis. J Am Heart Assoc 5(6), e003333.

Siiskonen, T., Ciraj Bjelac, O., Dabin, J., Diklic, A., Domienik Andrzejewska, J., Farah, J., Fernandez, J.M., Gallagher, A., Hourdakis, C.J., Jurkovic, S. Järvinen, H., Järvinen,J ., Knežević, Ž., Koukorava, C., Maccia, C., Majer, M., Malchair, F., Riccardi, L., Rizk, C., Sanchez, R., Sandborg, M., Sans Merce, M., Segota, D., Sierpowska, J., Simantirakis, G., Sukupova, L., Thrapsanioti, Z., Vano, E., 2016. Establishing the European diagnostic reference levels for interventional cardiology, Physica Medica 54, 42-48 